\title{
Cyclic behavior of steel I-beams modified by a welded haunch and reinforced with GFRP
}

\author{
O. Ozgur Egilmez*, Deniz Alkan and Timur Ozdemir \\ Dept. of Civil Engineering, Izmir Inst. of Technology, Izmir, 35430, Turkey
}

(Received July 25, 2009, Accepted August 7, 2009)

\begin{abstract}
Flange and web local buckling in beam plastic hinge regions of steel moment frames can prevent beam-column connections from achieving adequate plastic rotations under earthquake-induced forces. Reducing the flange-web slenderness ratios (FSR/WSR) of beams is the most effective way in mitigating local member buckling as stipulated in the latest seismic design specifications. However, existing steel moment frame buildings with beams that lack the adequate slenderness ratios set forth for new buildings are vulnerable to local member buckling and thereby system-wise instability prior to reaching the required plastic rotation capacities specified for new buildings. This paper presents results from a research study investigating the cyclic behavior of steel I-beams modified by a welded haunch at the bottom flange and reinforced with glass fiber reinforced polymers at the plastic hinge region. Cantilever I-sections with a triangular haunch at the bottom flange and flange slenderness ratios higher then those stipulated in current design specifications were analyzed under reversed cyclic loading. Beam sections with different depth/width and flange/web slenderness ratios (FSR/WSR) were considered. The effect of GFRP thickness, width, and length on stabilizing plastic local buckling was investigated. The FEA results revealed that the contribution of GFRP strips to mitigation of local buckling increases with increasing depth/width ratio and decreasing FSR and WSR. Provided that the interfacial shear strength of the steel/GFRP bond surface is at least $15 \mathrm{MPa}$, GFRP reinforcement can enable deep beams with FSR of 8-9 and WSR below 55 to maintain plastic rotations in the order of 0.02 radians without experiencing any local buckling.
\end{abstract}

Keywords : existing steel buildings; plastic local buckling; glass fiber reinforced polymers; stability.

\section{Introduction}

Seismic design of welded steel moment frames is generally based on the strong column-weak beam concept, in which the majority of energy dissipation is anticipated to occur by inelastic deformations in beams through the formation of plastic hinges near column faces. Seismic provisions, such as Eurocode- 8 (2003) and AISC (2005a), require beam-column connections to sustain interstory drift angles of at least 0.02 and 0.035-0.04 radians for intermediate and special moment frames (IMF and SMF), respectively, without any significant strength degradation; targeting a ductile behavior under earthquake induced forces. The ductility of welded beam-column connections depends primarily on three failure modes: a- fracture of beam flange to column groove welds; b- lateral torsional buckling (LTB) of beams; c- flange/web local buckling (FLB/WLB) at the plastic hinge region of beams. Most of the research conducted after

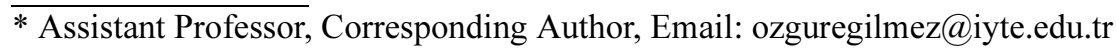


the 1994 Northridge (US) and 1995 Kobe (Japan) earthquakes focused on stress reduction methodologies and improvement of welding procedures to overcome the brittle weld fractures widely observed in welded SMFs in the aftermath of these earthquakes (ex: Nakashima, et al. 1998, SAC 1996, Uang, et $a l .2000$ ). Based on the findings from these researches new design guidelines and modification methods have been developed for new and existing steel moment frames, respectively, in order to overcome the brittle weld fractures and improve the plastic rotation capacity of welded connections (FEMA 2000a, FEMA 2000b, AISC 1999). Some typical recommendations include providing a reduced beam, welded haunch, or bolted bracket modification; as well as replacing the beam flange to column groove welds with a weld metal with higher Charpy V-Notch toughness. Fig. 1 depicts a pre-Northridge bolted web welded flange connection modified by a welded haunch at the bottom flange.

Although brittle weld fractures can now be satisfactorily mitigated for new and existing welded steel moment frame connections with post-Northridge design guidelines and modification methods, inelastic local buckling of beam flanges and webs is still a threat for the ductility and stability of structural members. In current seismic design codes (AISC 2005a, Eurocode-8 2003) local instabilities are controlled by limiting flange-web slenderness ratios. However, the rotation capacities expected from beam-column connections have increased as a result of post-Northridge and post-Kobe research. Hence, especially older structures that lack adequate slenderness ratios are vulnerable to local member buckling and thereby system-wise instability due to overloads such as earthquakes or other extreme events prior to reaching the required plastic rotation capacities specified for new buildings. Okazaki, et al. (2006) and Nakashima, et al. (2002 and 2003) have investigated the stability requirements for beams in steel SMF under earthquake induced forces and proposed even more stringent limits for unbraced length and widththickness ratios to control instabilities during large plastic rotations. Furthermore, even higher levels of

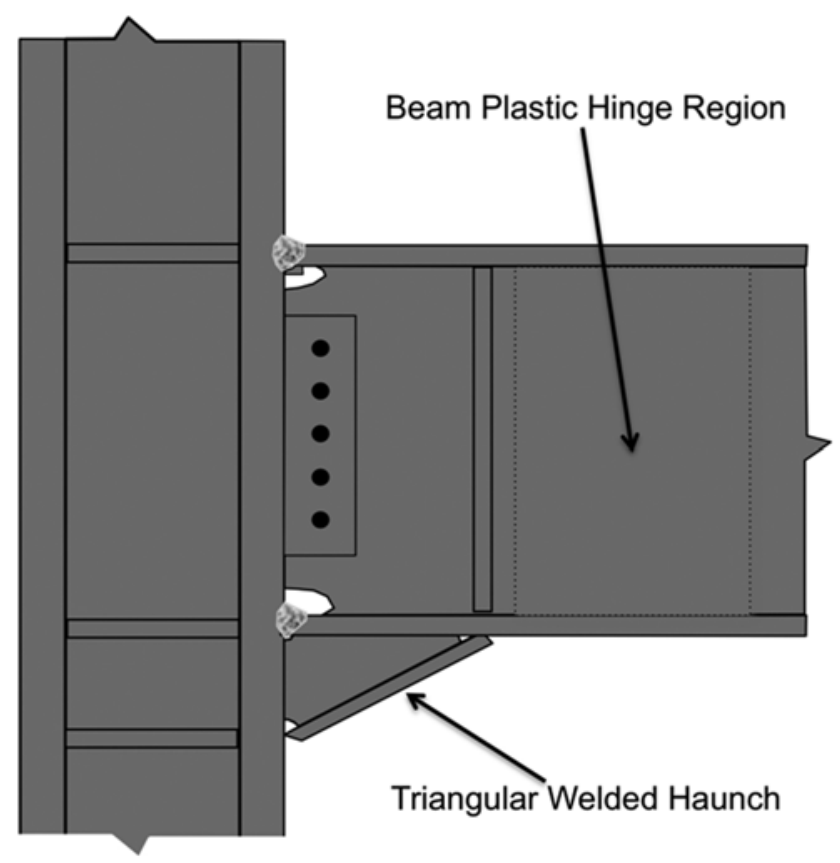

Fig. 1 Typical pre-Northridge bolted web - welded flange connection modified by a welded haunch at bottom flange 
plastic rotations than those stipulated in provisions may also be needed for buildings in soft soils, irregular buildings, and important structures. In addition, the repair of local buckles is an expensive and challenging application. Hence, mitigation of local inelastic instabilities especially in older steel moment frame connections is an important task, which will not only improve the ductility of the structure, but will also minimize cumbersome repair works in the aftermath of extreme events.

As the use of fiber reinforced polymers (FRP) has increased in strengthening and repair of steel members in recent years, using FRPs in stabilizing local instabilities has also attracted attention (ex: Accord and Earls 2006). A research study was conducted at Izmir Institute of Technology to investigate the cyclic behavior of existing welded steel moment frame connections rehabilitated by a triangular haunch welded to the beam bottom flange and reinforced with glass FRP (GFRP) laminates. The research consisted of laboratory investigations and finite element analytical (FEA) studies. This paper presents results from the FEA studies. Cantilever I-sections with a triangular haunch at the bottom flange and flange slenderness ratios (FSR) higher then those stipulated in current design specifications were analyzed under reversed cyclic loading. Both bare beam and GFRP reinforced sections were investigated. The behavior of bare steel sections were then compared with those of steel sections reinforced with GFRP strips. The effects of GFRP thickness, width, and length on stabilizing local buckling were investigated. The flexural resistance of the beams at column face, together with interlaminar shear stresses in GFRP strips, and shear stresses at the beam-GFRP binding surface were also examined.

Background information will be presented first, followed by the description and verification of the finite element model, as well as an overview of the study. Results from the FEA studies and recommendations on the use of GFRP laminates for different slenderness ratios will then be presented. The paper is concluded by a brief summary and conclusions.

\section{Background and previous work}

The high stiffness/strength to weight ratios of FRP materials, combined with their resistance to corrosion have increased their use in repair and strengthening of steel members. Generally, high modulus carbon FRP (CFRP) laminates with elastic modulus similar to that of steel are preferred in strengthening applications. On the other hand, GFRP has a much smaller modulus than that of steel, which limits its use in strengthening applications. However, this modulus mismatch is an asset when the primary goal is to stabilize inelastic local buckling with the least possible strength increase in the section. A strength increase in the beam section is not desired in steel moment frame connections because such an increase will result in higher forces in beam-column welds, which may exceed the design moment capacity of the connection. In a study by Accord and Earls (2006) it was observed that in a steel-GFRP composite system, while the low modulus of GFRP as compared to that of steel will not allow a significant strength increase in the steel section, its compressive strength can enable GFRP strips to maintain their flexural strength to provide bracing to the underlying steel in the plastic hinge region. This type of a composite action will enhance the plastic rotation capacity of the plastic hinge region; provided that an early debonding or GFRP fracture do not control the behavior.

The most significant work on stability of local buckling utilizing FRP composites is a finite element based study conducted by Accord and Earls (2006). In this study, Accord and Earls performed finite element analyses on cantilever steel beams with GFRP strips under monotonic loading and investigated the contribution of GFRP strips to the plastic rotation capacity and flexural strength of different sections. The plastic rotation capacity of the beam sections was shown to increase significantly, whereas the 
flexural strength increase in the sections was in the order of 20 to $25 \%$. However, the study did not focus on the response of the bond surface between steel and GFRP. Sayed-Ahmed (2004) also performed a finite element study in which CFRP strips were used on the compression region of the webs of I-beams and investigated the contribution of CFRP strips in delaying local web buckling. The results of the parametrical study showed that through the use of CFRP strips the local buckling of the web could be delayed resulting in critical load and strength increase. Ekiz, et al. (2004) conducted an experimental study investigating the energy dissipating capacity of double channel truss members under reversed cycling loading, which were wrapped by CFRP around the plastic hinge region. The test results showed that CFRP wrapping could increase the size of the yielded plastic hinge region and inhibit occurrence of local buckling.

\section{Finite element model and overview of study}

The three dimensional finite element program ANSYS (2007) was used to conduct FEA studies on the cyclic behavior of beams modified by a triangular haunch welded to the beam bottom flange and reinforced with GFRP strips. A half span steel frame model was adopted in the study as shown in Fig. 2. The column was modeled as a rigid bar; whereas the beam, triangular haunch, and the stiffener at the end of the haunch were modeled using eight-node quadrilateral shell elements with six degrees of freedom per node. This element possesses plasticity, large deflection, and large strain capabilities. The flange and web nodes of the beam and the triangular haunch at the end adjacent to the column face were coupled to the coinciding column nodes of the rigid column elements in all directions ( 3 displacements: UX, UY, UX, and 3 rotations: ROTX, ROTY, ROTZ) to form a fixed end connection. The nodes at the

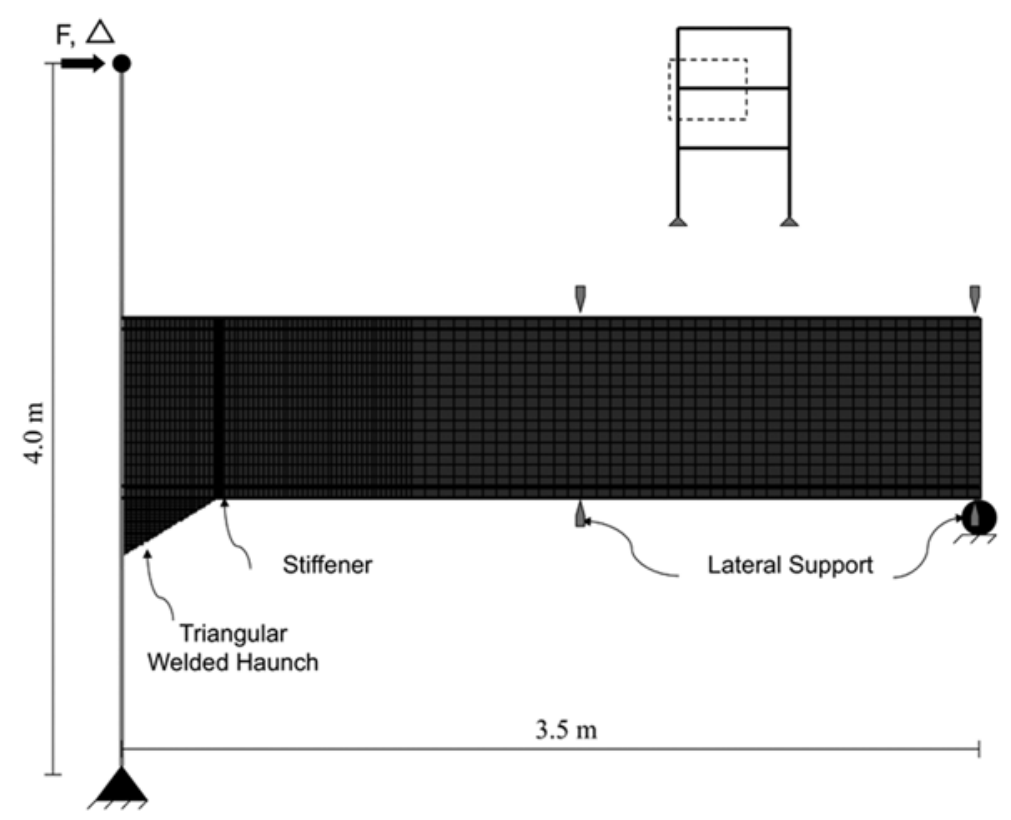

Fig. 2 Half span steel frame model 
bottom flange face of the web and flange of the triangular haunch were coupled to the coinciding bottom flange nodes of the beam in all directions to simulate the weld between the beam bottom flange and triangular haunch. The other end of the beam was supported by a roller; unconstrained in the longitudinal direction and constrained in the vertical direction. The beam was laterally restrained (both twist and out-of-plane motion) at mid-span and at the end with the roller support in order to ensure lateral torsional buckling did not control the failure mode. The column was simply supported at the bottom and supported by a roller at the top; unconstrained in the vertical direction and constrained in the longitudinal direction. Both top and bottom of the column were constrained against out of plane motion.

The length of the column and the beam were taken as $4,000 \mathrm{~mm}$ and 3,500 $\mathrm{mm}$, respectively. In the initial $1 / 3$ length of the beam from the fixed end the mesh sizes for the beam flanges and web were $16.5 \times 20 \mathrm{~mm}$ and $47 \times 20 \mathrm{~mm}$, respectively. The mesh sizes for the remainder of the beam was $16.5 \times 58 \mathrm{~mm}$ in the flanges and $47 \times 58 \mathrm{~mm}$ in the web. Both geometric and material non-linearity was considered. The yield strength $\left(F_{y}\right)$ and elastic modulus $(E)$ of steel were taken as $345 \mathrm{MPa}$ and 200 $\mathrm{GPa}$, respectively. A bilinear kinematic hardening rule was adopted for the stress-strain behavior of steel, with a secondary stiffness equal to $1 / 100$ of the elastic modulus. The effects of initial imperfections were also considered in the model, similar to the procedure followed by Accord and Earls (2006). A linear eigenvalue buckling analyses was performed for each beam section prior to non-linear analyses in which the cantilever beam was displaced towards the top flange. The displacement field obtained from the first eigenmode was then scaled by a factor of $\mathrm{L} / 1000$ and applied to the model geometry to create the initial imperfections. The factor of L/1000 is selected based on the permissible out of straightness specified in AISC (2005b).

GFRP laminates and epoxy resin used to attach GFRP to the steel surface were jointly modeled using layered eight-node solid elements with three degrees of freedom per node (translations in the nodal $X$, $\mathrm{Y}$, and $\mathrm{Z}$ directions). The initial layer of the element adjacent to the flange shell elements was treated as the epoxy resin and the other layers were treated as GFRP laminates. The thickness of each GFRP layer and epoxy resin were taken as $0.9 \mathrm{~mm}$ and $0.5 \mathrm{~mm}$, respectively. The mechanical properties of GFRP and interfacial surface between steel and GFRP were determined through laboratory tests confirming to ASTM standards performed by Guven at Izmir Institute of Technology (Guven 2009). Guven used $0^{\circ} \%$ $+45^{\circ} / 90^{\circ} /-45^{\circ}$ oriented glass fibers provided by METIX Co. and epoxy resin DTE/1000/1001 provided by DURATEK Co. Guven's test results indicated that the compression modulus of GFRP material in $0^{\circ}$ was $10 \mathrm{GPa}$. The elastic modulus of the epoxy resin was taken from the manufacturer's brochures as $2.6 \mathrm{GPa}$. Poisson's ratio was assumed as 0.3 for all materials. The finite element model of the cantilever beam with the triangular haunch and GFRP strips is shown in Fig. 3.

Cyclic loading was applied to the beams as drifts to the tip of the rigid column element, according to the loading sequence shown in Fig. 4. The rotation, $\theta$, shown in Fig. 4 represents the rotation of the beam at the fixed end; which is also equal to the rotation of the rigid column element. The sequence is identical to the loading sequence defined in AISC (2005a) for cyclic tests of beam-to-column moment connections in SMF and IMF; except that the initial elastic cycles were omitted.

The validity of the FEA simulation was verified by comparing the cyclic behavior of a wide flange Isection with that of the FEA simulation. The test used in the verification study was a full-scale cantilever beam test conducted at the structural engineering laboratory of Izmir Institute of Technology. The beam was a European wide flange beam, HE400AA, with a depth of $378 \mathrm{~mm}$, web thickness of $9.5 \mathrm{~mm}$, flange thickness of $13 \mathrm{~mm}$, and width of $300 \mathrm{~mm}$. The fixed end of the beam was modified by a welded haunch at the bottom flange. The cantilever beam was loaded cyclically similar to the loading protocol defined in AISC (2005a) for cyclic tests of beam-to-column moment connections in SMF and IMF. A 


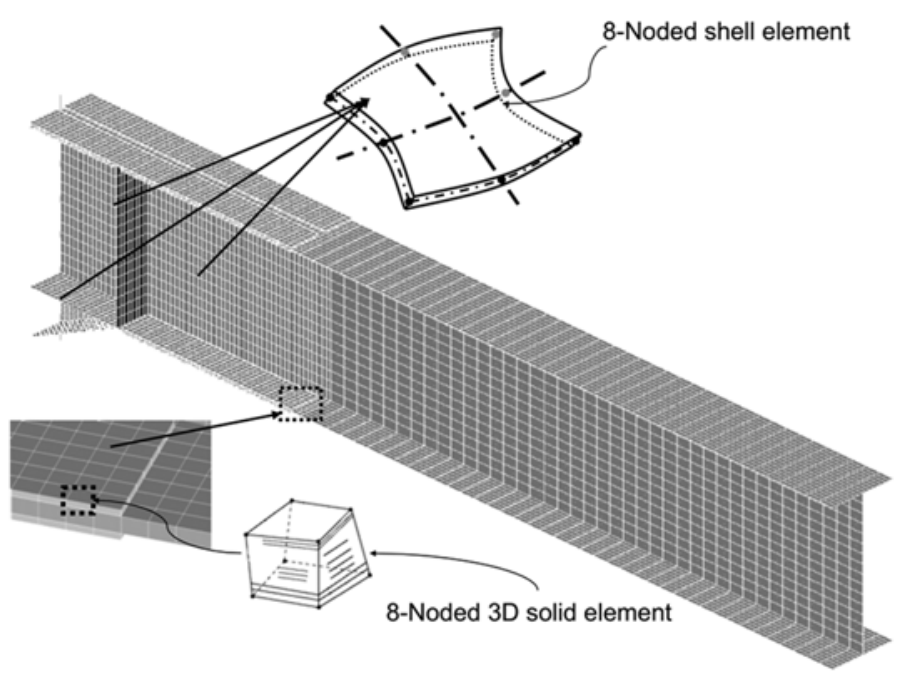

Fig. 3 Finite element model of cantilever beam with triangular haunch and GFRP strips

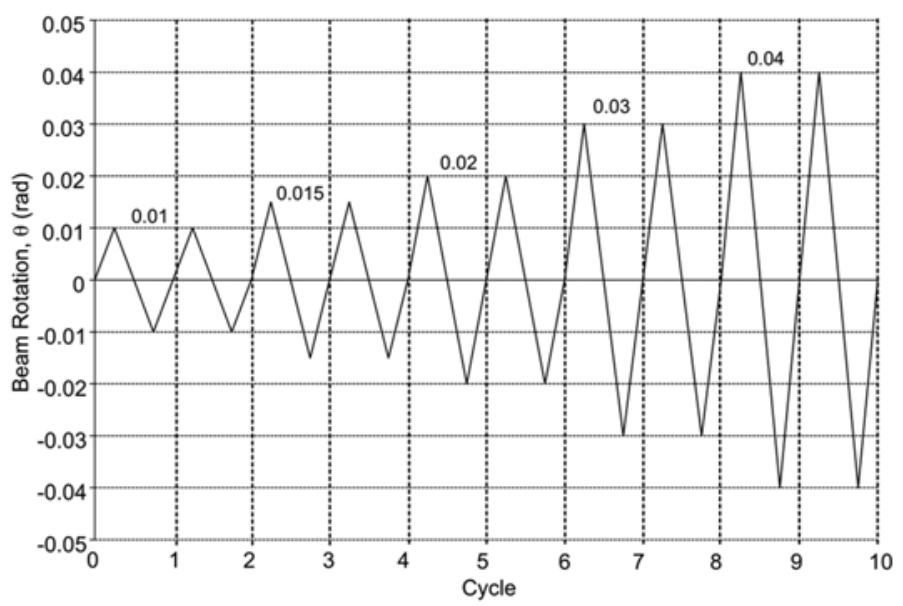

Fig. 4 Loading protocol followed in FEA studies

photograph of the HE400AA beam in the test setup and the loading sequence followed in the test are shown in Figs. 5 and 6, respectively. Due to the fact that the laboratory facilities did not have a strong wall, a strong steel frame was constructed and the test beam was bolted to it as seen in Fig. 5. Since the small displacements in the steel frame that would occur in the test could not be predicted prior to the actual test, slight deviations from the AISC (2005a) loading protocol were inevitable during testing.

Fig. 7 shows the load-fixed end rotation behavior of the HE400AA test beam and FEA simulation. The test was stopped at the second cycle of 0.03 radians of rotation when the load started to drop. As can be seen from the figure the FEA model predicted the behavior of the test beam very well. The only slight deviation occurred at the second cycle of 0.03 rad of rotation, where the FEA model reached only up to about $94 \%$ of the moment capacity of the test beam at positive rotation. This was probably due to 


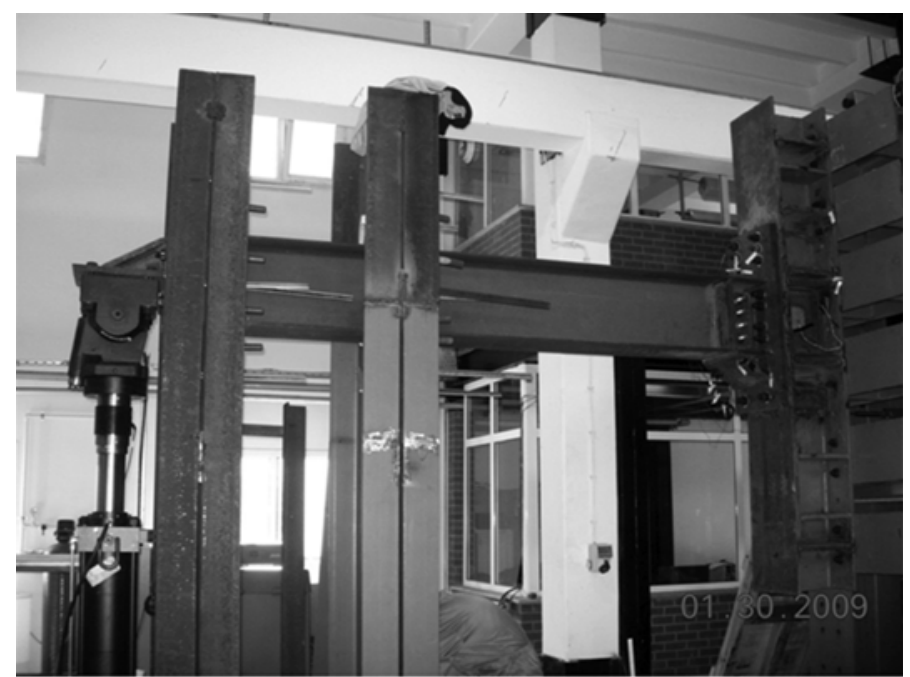

Fig. 5 Photograph of HE400AA test specimen in the test setup

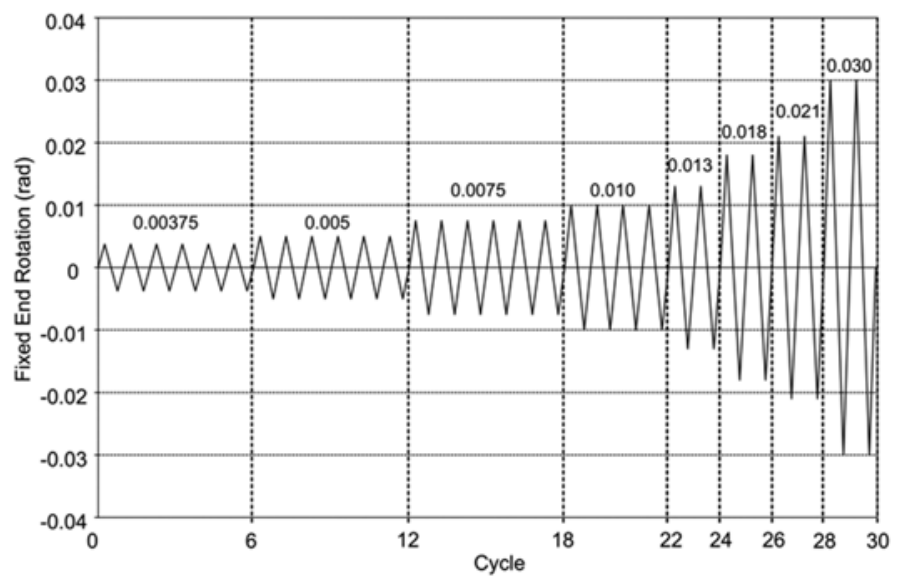

Fig. 6 Loading sequence followed in the cyclic test

the fact that the connection between the welded haunch stiffener and the flanges was not exactly simulated in the model. In the test beam the $25 \mathrm{~mm}$ thick stiffeners were fillet welded to the flanges on both sides. This type of a connection provided a $45-50 \mathrm{~mm}$ wide and $130 \mathrm{~mm}$ long rigid area on the flanges where the stiffeners were welded. In the FEA model however, the coinciding nodes of the top and bottom elements of the stiffeners were coupled to the flange elements' coinciding nodes along a single line. Although all six degrees of freedoms were coupled, the connection that was simulated in the model was more flexible than the connection provided in the actual beam. Hence, the flanges of the FEA model were more vulnerable to local buckling than the flanges of the actual beam.

The steel I-sections considered in the study consisted of beam sections with flange slenderness ratios exceeding the flange slenderness limits set forth in current seismic design specifications. In AISC (2005a) 


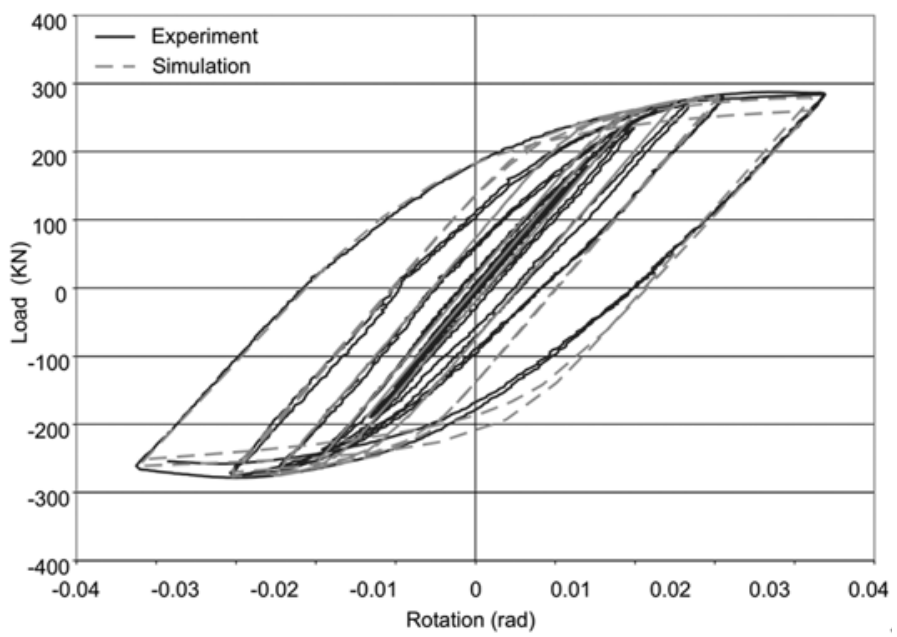

Fig. 7 Load-Rotation behavior of HE400AA beam and finite element simulation

limiting slenderness ratios for flanges and webs of rolled or built-up I shaped sections in flexural compression are 7.2 and 59, respectively, for SMF with $F_{y}=345 \mathrm{MPa}$ and $E=200 \mathrm{GPa}$. Fig. 8 shows the European and US wide-flange beams with FSR greater than 7.2. It can be seen in Fig. 8 that the flange and web slenderness ratios (FSR and WSR) of deep beams $(2<$ depth/width $<3)$ range between 7.5-9.5 and 43-57, respectively, and for shallow beams $(1<$ depth/width $<2)$ FSR and WSR range between 7.5-13.5 and 20-48, respectively. Three different beam depth/width $\left(d / b_{f}\right)$ ratios were selected: $2.79,2.1$, and 1.38. The flange width was taken as $265 \mathrm{~mm}$ for all sections and the desired $d / b_{f}$ ratios were obtained by changing the beam depth. Beam depths were $740,556.5$, and $365 \mathrm{~mm}$ for $d / b_{f}$ ratios of $2.79,2.1$, and 1.38 , respectively. It can be seen in Fig. 8 that the flange slenderness ratios of the majority of the sections are between 8 and 10 . Therefore, for all $d / b_{f}$ ratios FSR of 8,9 , and 10 were

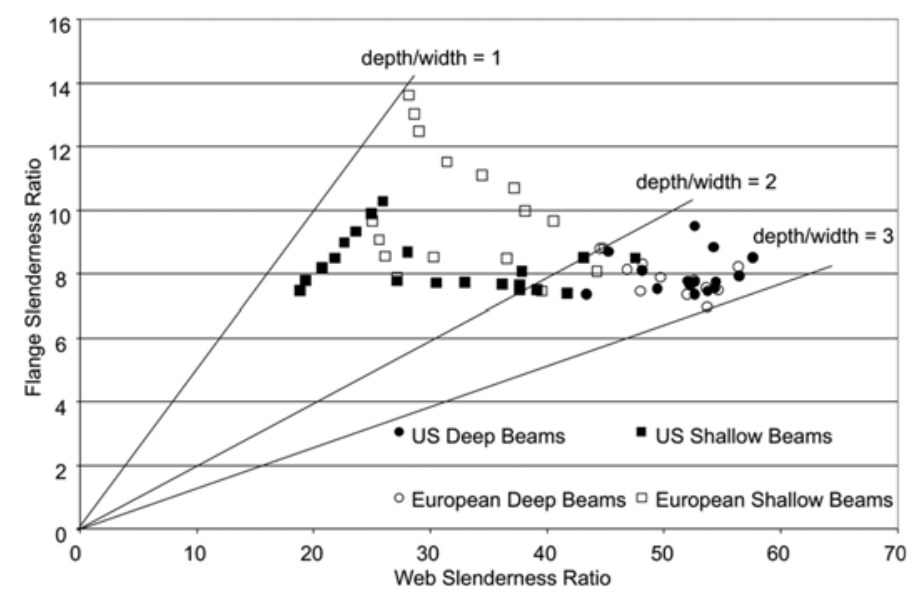

Fig. 8 US and European wide flange beams with FSR greater than 7.2 
investigated. Since flange and web local buckling are not independent from each other, different WSR were examined for each flange slenderness ratio. It was observed in Fig. 8 that as the $d / b_{f}$ ratio of the wide flange sections decreased, the WSR of the sections also decreased. Therefore, for sections with $d / b_{f}$ $=2.79,2.1$, and 1.38 WSR of 40-45-50-55-60, 40-45-50, and 30-35-40 were selected, respectively. The desired FSR and WSR values were obtained by changing the flange and web thicknesses of the beams. The geometric properties of the beams modeled in this study are presented in Table 1 . The depth and length of the triangular haunches were taken as $228 / 380,167 / 278$ and $114 / 190 \mathrm{~mm}$ for $d / b_{f}=2.79,2.10$, and 1.38 , respectively. The triangular haunch dimensions were obtained following the guidelines presented in AISC (1999).

Table 1 Geometric properties of beam sections used in the FEA study

\begin{tabular}{ccccccc}
\hline \hline $\begin{array}{c}\text { Section } \\
\text { Designation }\end{array}$ & $\begin{array}{c}\text { Beam Length } \\
(\mathrm{mm})\end{array}$ & $\begin{array}{c}\text { Beam Depth } \\
(\mathrm{mm})\end{array}$ & $\begin{array}{c}\text { Flange Width } \\
(\mathrm{mm})\end{array}$ & $\begin{array}{c}\text { Flange } \\
\text { Thickness }(\mathrm{mm})\end{array}$ & $\begin{array}{c}\text { Web } \\
\text { Thickness }(\mathrm{mm})\end{array}$ & $\begin{array}{c}\text { Depth/Width } \\
\text { Ratio }\end{array}$ \\
\hline D740-F8W40 & 3500 & 740 & 265 & 16.56 & 18.50 & 2.79 \\
D740-F8W45 & 3500 & 740 & 265 & 16.56 & 16.44 & 2.79 \\
D740-F8W50 & 3500 & 740 & 265 & 16.56 & 14.80 & 2.79 \\
D740-F8W55 & 3500 & 740 & 265 & 16.56 & 13.45 & 2.79 \\
D740-F8W60 & 3500 & 740 & 265 & 16.56 & 12.33 & 2.79 \\
D740-F9W40 & 3500 & 740 & 265 & 14.72 & 18.50 & 2.79 \\
D740-F9W45 & 3500 & 740 & 265 & 14.72 & 16.44 & 2.79 \\
D740-F9W50 & 3500 & 740 & 265 & 14.72 & 14.80 & 2.79 \\
D740-F9W55 & 3500 & 740 & 265 & 14.72 & 13.45 & 2.79 \\
D740-F9W60 & 3500 & 740 & 265 & 14.72 & 12.33 & 2.79 \\
D740-F10W40 & 3500 & 740 & 265 & 13.25 & 18.50 & 2.79 \\
D740-F10W45 & 3500 & 740 & 265 & 13.25 & 16.44 & 2.79 \\
D740-F10W50 & 3500 & 740 & 265 & 13.25 & 14.80 & 2.79 \\
D740-F10W55 & 3500 & 740 & 265 & 13.25 & 13.45 & 2.79 \\
D740-F10W60 & 3500 & 740 & 265 & 13.25 & 12.33 & 2.79 \\
D556-F8W40 & 3500 & 556 & 265 & 16.56 & 13.90 & 2.10 \\
D556-F8W45 & 3500 & 556 & 265 & 16.56 & 12.36 & 2.10 \\
D556-F8W50 & 3500 & 556 & 265 & 16.56 & 11.12 & 2.10 \\
D556-F9W40 & 3500 & 556 & 265 & 14.72 & 13.90 & 2.10 \\
D556-F9W45 & 3500 & 556 & 265 & 14.72 & 12.36 & 2.10 \\
D556-F9W50 & 3500 & 556 & 265 & 14.72 & 11.12 & 2.10 \\
D556-F10W40 & 3500 & 556 & 265 & 13.25 & 13.90 & 2.10 \\
D556-F10W45 & 3500 & 556 & 265 & 13.25 & 12.36 & 2.10 \\
D556-F10W50 & 3500 & 556 & 265 & 13.25 & 11.12 & 2.10 \\
D365-F8W30 & 3500 & 380 & 265 & 16.56 & 12.66 & 1.38 \\
D365-F8W35 & 3500 & 380 & 265 & 16.56 & 10.86 & 1.38 \\
D365-F8W40 & 3500 & 380 & 265 & 16.56 & 9.50 & 1.38 \\
D365-F9W30 & 3500 & 380 & 265 & 14.72 & 12.66 & 1.38 \\
D365-F9W35 & 3500 & 380 & 265 & 14.72 & 10.86 & 1.38 \\
D365-F9W40 & 3500 & 380 & 265 & 14.72 & 9.50 & 1.38 \\
D365-F10W30 & 3500 & 380 & 265 & 13.25 & 12.66 & 1.38 \\
D365-F10W35 & 3500 & 380 & 265 & 13.25 & 10.86 & 1.38 \\
D365-F10W40 & 3500 & 380 & 265 & 13.25 & 9.50 & 1.38 \\
\hline & & & & &
\end{tabular}




\section{FEA results}

The sections listed in Table 1 were analyzed both with and without GFRP strips in order to observe the effects of GFRP strips to the cyclic behavior of each beam section. In evaluating the cyclic behavior of sections reinforced with GFRP strips the moment at the column face, shear stress of the interface between steel and GFRP, and interlaminar shear stress of GFRP strips were checked at every load step prior to local buckling to make sure the design moment of the connection, shear strength of the interface, and interlaminar shear strength of the GFRP strips were not exceeded. The maximum design moment of the connection was taken as $1.2 M_{p}$, which is in correlation with AISC (2005c).

There are many potential failure modes of a steel-FRP composite system under flexure. The major ones that involve the FRP material and the adhesive layer are tensile rupture or compressive failure of the FRP material and debonding of the steel-FRP bond surface. Among these failure modes, debonding is often the weakest link (Cadei, et al. 2004). The most significant stresses in a bond layer between steel and FRP are the longitudinal shear stresses and through the thickness normal stresses, which is also known as peeling stress. These stresses are generally the highest at the ends of the FRP laminates or in the regions of large local deformations such as buckling. A tensile normal stress at the adhesive layer may lead to peeling of the FRP away from the steel surface and accelerate debonding. However, the negative effects of the peeling stresses are neglected in this study and focus is mainly given to the longitudinal shear stresses.

Recently, many studies have been conducted that investigated potential ways to mitigate peeling stresses and premature debonding. Some of the recommended applications of these research investigations include reverse tapering the edges of the FRP laminates (Schnerch, et al. 2007) and providing crosswraps (Chen and Das 2009). In addition, Cadei, et al. (2004) showed that for system with FRP laminates of small thickness, which is the case in this study, the peeling stresses were negligible compared with shear stresses. Nevertheless, it is assumed in this study that the ends of the FRP material are anchored to the steel surface in some way and that peeling stresses do not affect debonding. Furthermore, the increase in peeling stresses in the buckled regions is not of interest in this research, because the longitudinal shear stresses in the adhesive layer are always checked against the shear strength of the adhesive layer prior to local buckling. It is further assumed that the steel-GFRP composite action ends when either of the following takes place: a- local buckling initiates; $b$ - interfacial shear strength of the steel-GFRP bond layer is exceeded prior to local buckling; or c- interlaminar shear strength of the GFRP laminates is exceeded prior to local buckling. The tensile and compressive stresses that developed on the GFRP strips were much lower than the measured tensile and compressive strengths of the GFRP material and therefore were not discussed in the results.

In order to determine the interfacial and interlaminar shear strength values that would be used in the study, a literature review was conducted. It was seen that the interfacial shear strength of steel-GFRP surfaces bonded with commonly used epoxies could reach up to 20-25 MPa (El Damatty and Abushagur 2003, Boone 2002) and the interlaminar shear strength of commonly used GFRP materials could reach up to $20 \mathrm{MPa}$ (Lili, et al. 2008). A resistance factor of 0.75 was applied to the lower limit of the above interfacial shear strengths and a resistance factor of 0.90 was applied to the above interlaminar shear strength. Hence, shear strength of the interface and interlaminar shear strength of the GFRP strips were taken as $15.0 \mathrm{MPa}$ and $18.0 \mathrm{MPa}$, respectively. A lower resistance factor was accepted for the interfacial shear strength as compared to that for the interlaminar shear strength. This was due to the fact that bonding GFRP strips to steel surfaces involves many steps that need to be performed carefully and could be difficult to control out in the field. 


\section{Optimum location, length, and width of GFRP strips}

In order to determine the optimum location, length, and width of GFRP strips a series of analyses were conducted with a beam section having a depth/width ratio of 2.79 , depth of $740 \mathrm{~mm}$, width of $265 \mathrm{~mm}$, FSR of 10, and WSR of 65. Although this section (D740-F10W65) is not among the sections listed in Table 1, the response of the sections listed in Table 1 to different GFRP length, width, thickness, and placement configurations were similar to that of section D740-F10W65. Three different configurations were considered for GFRP placement: 1- Bottom of the top flange and top of the bottom flange outside the welded haunch region (Fig. 9), 2- Both sides of the top and bottom flanges outside the welded haunch region (Fig. 10), and 3- Both sides of the top flange outside and inside the welded haunch region and both sides of the bottom flange only outside of the welded haunch region (Fig. 11). As seen in these figures the length, width, and thickness of GFRP strips are identified as ratios of beam depth, beam width, and flange thickness, respectively. The length of GFRP strips denotes the length beyond the welded haunch stiffener in the plastic hinge region of the beam. The results obtained from several analyses with different GFRP widths, lengths, and locations are presented in Table 2.

Prior to discussion of the results in Table 2, the $M / M_{p}-\theta$ (normalized moment at column face rotation at fixed end) behavior of a beam with and without GFRP will be explained to clarify how the values presented in Table 2 were obtained. Fig. 12 shows the $M / M_{p^{-}} \theta$ behaviors of a bare beam and beam with GFRP. The beam depth, width, $d / b_{f}$ ratio, FSR, and WSR were $740 \mathrm{~mm}, 265 \mathrm{~mm}, 2.79,9$, and 55, respectively. The GFRP configuration was identical to the one shown in Fig. 11. The GFRP length, thickness, and width were $d_{b}$, where $d_{b}$ is equal to depth of the beam, $0.37 t_{f}$ ( 3 layers at top and 3 layers at bottom of each flange $=3+3$ layers), where $t_{f}$ is equal to thickness of the flange, and $0.45 b_{f}$, where $b_{f}$ is equal to the flange width. Positive rotation (bending) corresponds to compression at the top flange and negative rotation (bending) corresponds to compression at the bottom flange. In the figure a drop in capacity indicates the occurrence of local buckling. It can be observed from the figure that for the bare beam the last cycles prior to local buckling were the $1^{\text {st }}$ cycle of $0.015 \mathrm{rad}$ of rotation and the $1^{\text {st }}$ cycle of $0.017 \mathrm{rad}$ of rotation at the bottom and top flanges, respectively. In other words, local flange buckling occurred at the $2^{\text {nd }}$ cycle of $0.015 \mathrm{rad}$ of rotation and the $1^{\text {st }}$ cycle of $0.02 \mathrm{rad}$ of rotation at bottom and
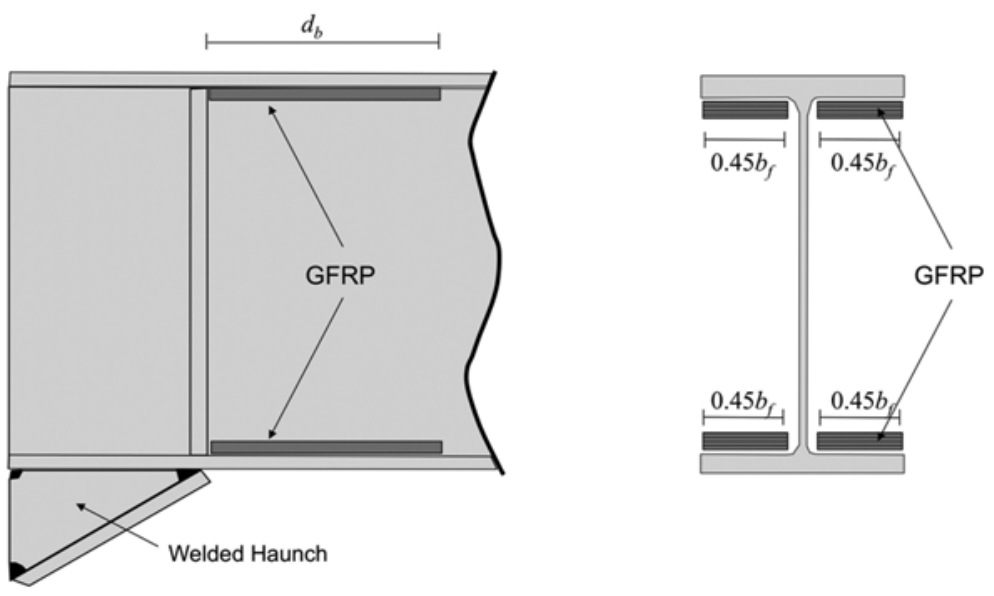

Fig. 9 GFRP placement: Configuration 1 

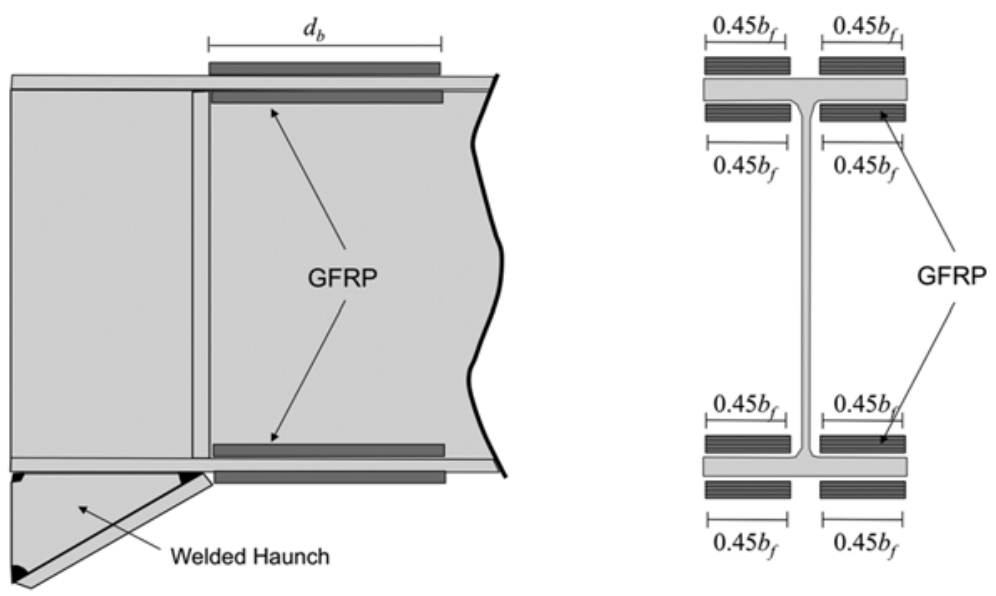

Fig. 10 GFRP placement: Configuration 2
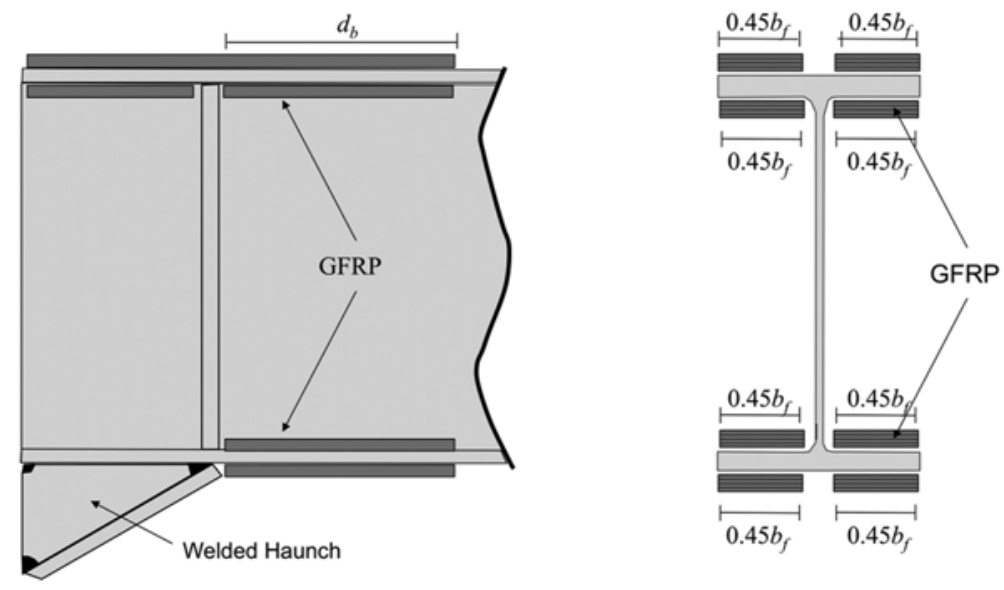

Fig. 11 GFRP placement: Configuration 3

top flanges, respectively. The fact that local buckling initiates at the bottom flange prior to the top flange is consistent with the applied initial imperfections.

For the GFRP reinforced beam the last cycles prior to local buckling were the $2^{\text {nd }}$ cycle of $0.015 \mathrm{rad}$ of rotation and the $1^{\text {st }}$ cycle of $0.02 \mathrm{rad}$ of rotations at the bottom and top flanges, respectively. The maximum shear stress at the interface and interlaminar shear stress at these cycles were 13.4 and 15.0 $\mathrm{MPa}$, respectively. The maximum interfacial shear stress was very close to the accepted interfacial shear strength of the bond surface between steel and GFRP. The maximum $M / M_{p}$ values were 0.99 and 1.08 for the beam with GFRP for negative and positive bending, respectively; which were lower than the design moment of the connection. The addition of GFRP to the steel section enabled the rotation capacities in positive and negative bending to increase by 1 cycle, whereas the increase in the moment capacity was minimal. Local distortions in the bottom flange observed in the model with GFRP at a rotation of $0.02 \mathrm{rad}$ are shown in Fig. 13. As can be seen from the figure major distortions occur in the flanges with 
Table 2 Analyses results for section D740-F10W65

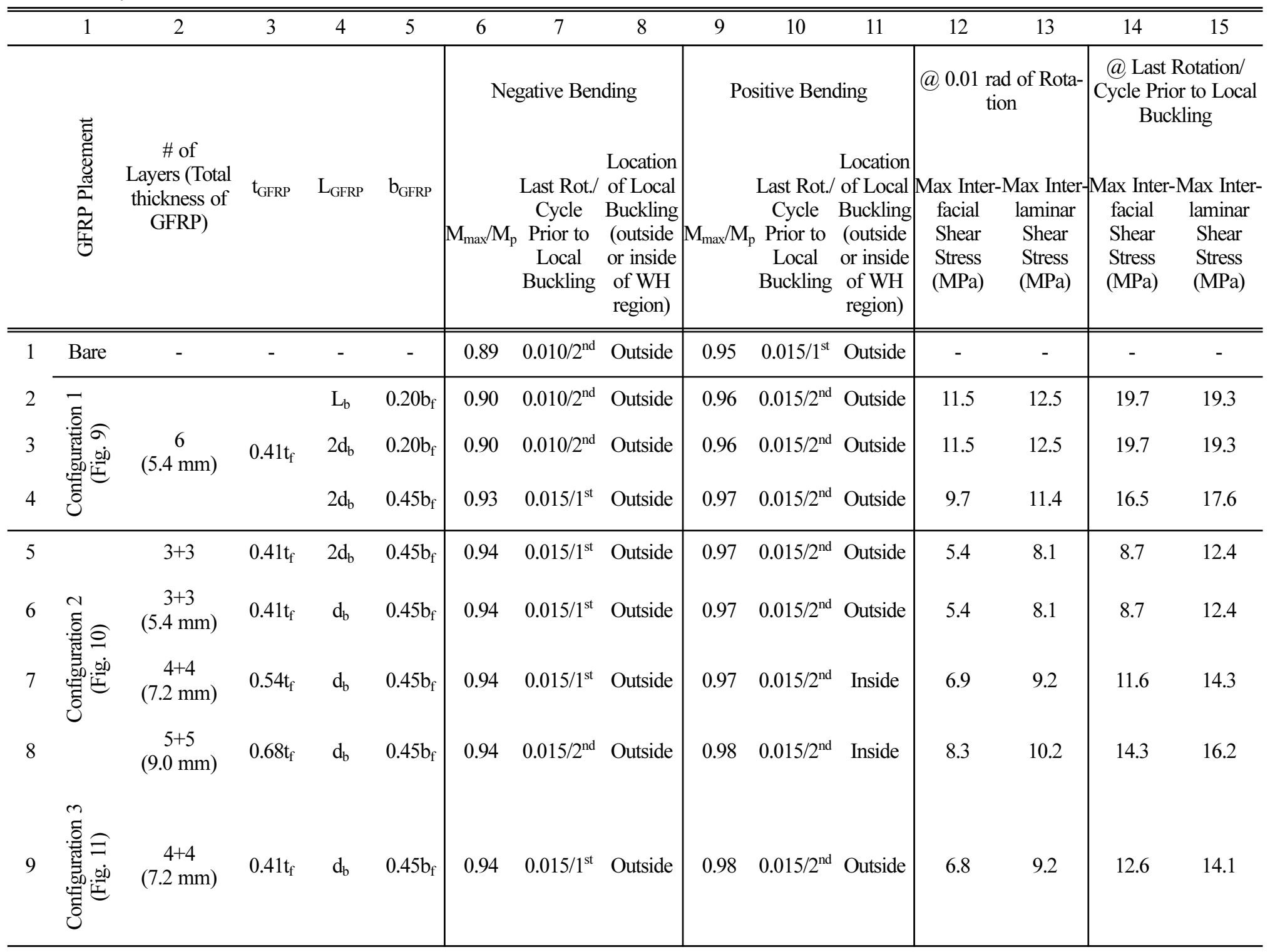




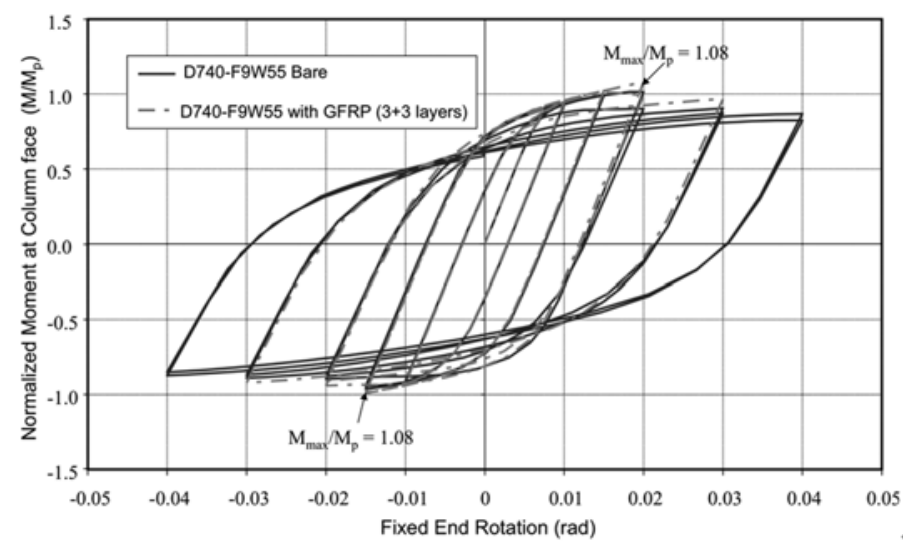

Fig. $12 M / M p-\theta$ relationships of D740-F9W55 section with and without GFRP

some kinking at the web adjacent to the distorted flange.

Table 2 presents results from a series of finite element analyses conducted with a $740 \mathrm{~mm}$ deep and $265 \mathrm{~mm}$ wide beam section. The depth/width ratio, FSR, and WSR of the section were $2.79,10$, and 65 , respectively. The effects of different GFRP length $\left(L_{G F R P}\right)$, width $\left(w_{\text {GFRP }}\right)$, thickness $\left(t_{\text {GFRP }}\right)$, and placement configurations (Fig. 9, 10, or 11) on the overall cyclic behavior of the beam section were examined. The first column indicates the placement configuration of GFRP strips. In the $2^{\text {nd }}, 3^{\text {rd }}, 4^{\text {th }}$, and $5^{\text {th }}$ columns layer number (6 layers imply GFRP placed on one side of the flanges as shown in Fig. 9, $3+3$ layers imply GFRP is placed on top and bottom of both flanges as shown in Fig. 10 or Fig. 11), thickness of

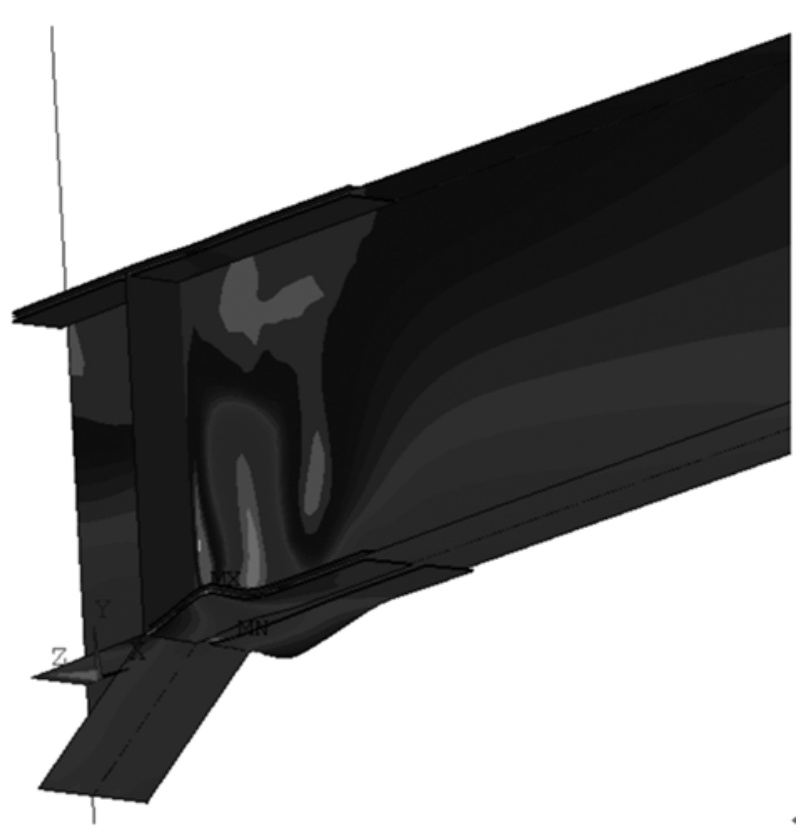

Fig. 13 Local flange buckling observed in bottom flange at $1^{\text {st }}$ cycle of 0.02 rad of rotation for D740-F9W55 
GFRP (as a ratio of flange thickness, $t_{f}$ ), length of GFRP (as a ratio of beam depth $d_{b}$ beyond the haunch stiffener), and width of GFRP (as a ratio of flange width, $b_{f}$, for each side of a flange) are presented, respectively. The $6^{\text {th }}$ and $9^{\text {th }}$ columns present $M_{\max } / M_{p}$ values for negative and positive bending, respectively. The $7^{\text {th }}$ and $10^{\text {th }}$ columns present the last rotation/cycle number achieved prior to local buckling for negative and positive bending, respectively. The $8^{\text {th }}$ and $11^{\text {th }}$ columns indicate whether buckling occurs inside or outside of the welded haunch region at the flanges.

The interfacial and interlaminar shear stresses were also examined at different load steps and results are presented in columns 12 through 15. The maximum interfacial shear stress at the surface between steel and GFRP and interlaminar shear stress in GFRP at the $2^{\text {nd }}$ cycle of 0.01 rad of rotation are presented in column 12 and 13, respectively. These are the largest stress values that develop at the top and bottom flanges at this rotation. The purpose of presenting these values is to compare the shear stresses of different GFRP systems at a fixed rotation prior to local buckling. In the $14^{\text {th }}$ and $15^{\text {th }}$ columns the maximum interfacial and interlaminar shear stresses are presented at the last rotation/cycle prior to local buckling for negative and positive bending, respectively. The maximum interfacial and interlaminar shear stresses occurred around the welded haunch stiffener. The values presented in columns 14 and 15 are the shear stress values that develop at the last rotation/cycle of the bottom flange. Due to the implemented imperfections the top flange buckled at a later rotation/cycle than the bottom flange. However, the maximum interfacial and interlaminar shear stress values for the top flange at the corresponding last rotation/cycle prior to local buckling were similar to the values given in columns 14 and 15 .

The first row of Table 2 contains information about the bare steel model. The $2^{\text {nd }}, 3^{\text {rd }}$, and $4^{\text {th }}$ rows are for steel-GFRP systems with 6 layers of GFRP (Fig. 9 with $t_{\text {GFRP }}=0.40 t_{f}$ ). The $5^{\text {th }}$ and $6^{\text {th }}$ rows are for systems with 3 layers of GFRP (Fig. 10 with $t_{G F R P}=0.20 t_{f}+0.20 t_{f}=0.40 t_{f}$ ) on each side of the flanges $(3+3$ layers). The total thickness of the GFRP strips in one flange for 6 layers and $3+3$ layers are identical. However, in 6 layer systems a thicker GFRP is placed on one side of the flanges, whereas in $3+3$ layer systems a thinner GFRP is placed on both sides of the flanges. Comparison of rows 2 and 3 shows that keeping the length of GFRP laminates at twice the beam depth beyond the welded haunch stiffener is identical to using full length GFRP laminates. For both of the systems maximum moments at column face, last rotation/cycle numbers, location of local buckling, maximum interfacial and interlaminar shear stresses at $0.01 \mathrm{rad}$ of rotation, and maximum interfacial and interlaminar shear stresses at last cycle prior to local buckling were identical.

In row 4 results from a steel-GFRP system with a GFRP length, thickness, and width of $2 d_{b}, 0.40 t_{f}$, and $0.45 b_{f}$, respectively, are presented. Increasing the width of the GFRP strips to $0.45 b_{f}$ from $0.20 b_{f}$ decreased the maximum interfacial and interlaminar shear stresses at $0.01 \mathrm{rad}$ of rotation to 9.7 and 11.4 $\mathrm{MPa}$ from 11.5 and $12.5 \mathrm{MPa}$, respectively. An increase in the last rotation/cycle number prior to local buckling was observed only in negative bending. The last rotation/cycle number prior to local buckling at negative bending for the system with a GFRP width of $0.20 b_{f}$ was $2^{\text {nd }}$ cycle of 0.01 rad of rotation; whereas for the system with GFRP width of $0.45 b_{f}$ this value increased to $1^{\text {st }}$ cycle of $0.015 \mathrm{rad}$ of rotation.

In order to further decrease the interfacial and interlaminar shear stresses, a system with GFRP placed on both sides of flanges were analyzed (rows 5 and 6 ), keeping the total thickness of GFRP the same. It was seen that using GFRP strips on both sides of flanges (Fig. 10) decreased the maximum interfacial and interlaminar shear stresses at $0.01 \mathrm{rad}$ of rotation to 5.4 and $8.1 \mathrm{MPa}$ from 9.7 and $11.4 \mathrm{MPa}$ (row 4), respectively. Another analysis was conducted to determine whether the length of the GFRP strips could further be decreased. Row 6 presents results from a system identical to the system in row 5 , except the length of the GFRP strips. Comparison of the results presented in rows 6 and 5 shows that 
decreasing the length of GFRP strips to $d_{b}$ from $2 d_{b}$ does not weaken the contribution of GFRP strips. For the system presented in row 6 the maximum interfacial and interlaminar shear stresses at last cycle prior to local buckling were 8.7 and $12.4 \mathrm{MPa}$, respectively. Since these values were smaller than the accepted interfacial and interlaminar shear stresses (15.0 and $18 \mathrm{MPa})$, the analyses were continued by increasing the layer number of GFRP.

Rows 7 and 8 present results from steel-GFRP systems with $4+4$ and 5+5 layers of GFRP, respectively. The major difference in behavior observed in systems with $4+4$ and $5+5$ layers of GFRP was a shift in the location of initial local buckling at the top flange. In the system with $3+3$ layers of GFRP initial top flange local buckling was observed just outside the welded haunch $(\mathrm{WH})$ region. However, in the systems with $4+4$ and 5+5 layers of GFRP initial top flange local buckling was observed inside the WH region adjacent to the column face. Increasing the bracing provided to the top flange outside the WH region inevitably forced local buckling to shift to other locations under high strains, such as the portion of the top flange adjacent to the column face. The presence of the welded haunch at the bottom flange prevented bottom flange local buckling to shift adjacent to the column face inside the WH region. As can be seen in columns 14 and 15 the maximum interfacial and interlaminar shear stresses increased as the thickness of the GFRP increased. The shear strength of the interfacial layer was exceeded in the system with $5+5$ layers of GFRP.

Since local flange buckling adjacent to the column face is not desirable, another analysis was conducted by providing GFRP at both outside and inside of the WH region (as shown in Fig. 11). The purpose of such an addition was to shift the top flange buckling back to the plastic hinge region just outside the welded haunch region. Row 9 presents results from a system with 4+4 layers of GFRP and GFRP configuration identical to the one shown in Fig. 11. The addition of the GFRP inside the welded haunch region did not have an effect on the rotation capacities prior to local buckling as compared to the behavior obtained from the system presented in row 7. However, the initiation of local buckling at the top flange was moved back to the plastic hinge region adjacent to the WH stiffener.

The results presented in Table 2 revealed that the contribution of GFRP strips to the cyclic behavior of steel beams modified by a welded haunch at the bottom flange was limited by the interfacial shear strength of the bonded layer between steel and GFRP. The optimum length and width of GFRP strips, which lead to the smallest interfacial and interlaminar shear stresses, were $d_{b}$ and $0.45 b_{f}$, respectively, and the optimum GFRP configuration was configuration 3 (Fig. 11).

Prior to conducting finite element analyses with the sections listed in Table 1, the writers also investigated the effects of modulus of elasticity of GFRP and placing GFRP also on the web to the cyclic behavior of beams. Table 3 presents results from analyses conducted on steel-GFRP systems with higher GFRP elastic modulus and different GFRP configurations. Rows 1 and 2 of Table 3 present results from bare beam and GFRP reinforced sections, respectively. The steel-GFRP system had $4+4$ number of GFRP layers placed according to configuration 3 (Fig. 11). The system in row 2 is the same system presented in row 9 of Table 2 . The systems in rows 3 and 4 are identical to the system in row 2, except the elastic modulus of GFRP. The elastic modulus of GFRP was taken as 20000 and 200000 MPa for the systems in rows 3 and 4, respectively. For the system presented in row 2 the elastic modulus of GFRP was taken as $10000 \mathrm{MPa}$. Finally in rows 5 and 6, results from a steel-GFRP steel system with GFRP (elastic modulus of $10000 \mathrm{MPa}$ ) placed also in the web are presented. The system in row 5 is reinforced with GFRP in the web outside the WH region for a distance $d_{b}$, in addition to the GFRP configuration shown in Fig. 11. The system in row 6 is reinforced with GFRP in the web both inside and outside the WH region.

Comparison of the results presented in rows 2,3 , and 4 shows that increasing the elastic modulus of 
Table 3 Analyses results for section D740-F10W65 with different GFRP modulus and placement

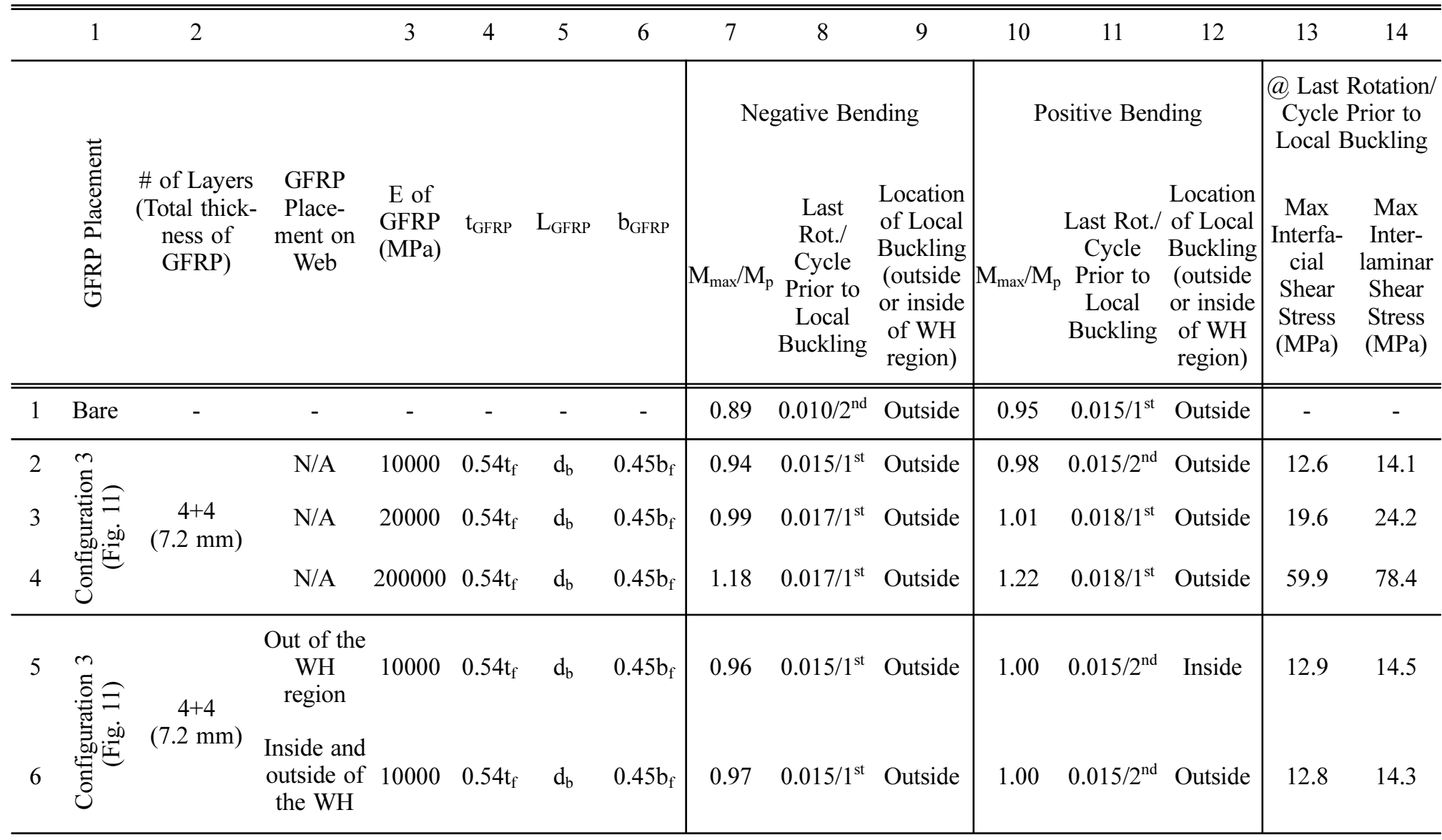


GFRP had a minor effect on the rotation capacities prior to local buckling for both the top and bottom flanges. However, the maximum interfacial and interlaminar shear stresses for both systems prior to local flange buckling increased beyond the accepted shear strengths. The interfacial and interlaminar shear stresses prior to local flange buckling jumped to 19.6/24.2 $\mathrm{MPa}$ and 59.9/78.4 MPa at the end of the $2^{\text {nd }}$ cycle of $0.015 \mathrm{rad}$ of rotation for the systems with GFRP modulus of 20000 and $200000 \mathrm{MPa}$, respectively. For the system with GFRP modulus of $200000 \mathrm{MPa}$, not only the maximum shear stresses but also the maximum moment at the column face increased considerably. The maximum normalized column moments $\left(M_{\max } M_{p}\right)$ for this system were 1.18 and 1.22 for negative and positive bendings, respectively. The design moment capacity of the connection in positive bending was exceeded.

The addition of GFRP on the web also did not have a major effect on the behavior (rows 5 and 6). The maximum column face moments and shear stresses at the last rotation prior to local buckling increased slightly for both configurations. The addition of GFRP on the web only at the outside of the welded haunch region (row 5) forced the location of initial local buckling to shift to the top flange inside the welded haunch region. The reason for such behavior is probably due to the fact that the addition of the GFRP on the web prevents the initiation of local buckling outside the welded haunch region and forces it to initiate inside the welded haunch region where the web is free of GFRP. Addition of GFRP to the web inside the welded haunch region shifted local buckling back to the plastic hinge region beyond the welded haunch stiffener at the flanges (row 6).

\section{Sections with depth/width ratio of $\mathbf{2 . 7 9}$}

The sections presented in Table 1 were analyzed with the GFRP configuration shown in Fig. 11. The width of GFRP was taken as $0.45 b_{f}$ and the length as $d_{b}$ beyond the haunch stiffener for all sections. Results from analyses conducted on sections with a depth/width ratio of 2.79 will be presented in this section. Prior to looking at the results in a table format the $M / M_{p}-\theta$ behavior of one of the sections will be presented. The normalized moment at the column face - rotation at fixed end $\left(M / M_{p}-\theta\right)$ behavior of section D740-F8W40 with and without GFRP is shown in Fig. 14. Three layers of GFRP on each side of the flanges were used. In the figure positive and negative rotations indicate compression on the top and bottom flanges, respectively. It can be observed from the figure that in the bare section strength degradation initiates at the end of the $2^{\text {nd }}$ cycle of $0.02 \mathrm{rad}$ of rotation and the $1^{\text {st }}$ cycle of $0.02 \mathrm{rad}$ of rotation for positive and negative bending, respectively. The strength degradations continue in the following rotations as the severity of local buckling increases and the normalized column moments at the column face at the end of the $2^{\text {nd }}$ cycle of 0.04 rad of rotation drop to 0.90 and 0.94 for positive and negative bendings, respectively. These values are higher than the minimum required flexural resistance at the column face $\left(0.80 \mathrm{M} / \mathrm{M}_{p}\right)$ at an interstory drift angle of $0.04 \mathrm{rad}$ for special moment frames as stated in AISC (2005a).

The addition of $3+3$ layers of GFRP to the steel section increases the rotation/cycle values prior to local buckling. For positive and negative bendings these values increase to the $1^{\text {st }}$ cycle of $0.025 \mathrm{rad}$ of rotation and the $2^{\text {nd }}$ cycle of $0.02 \mathrm{rad}$ of rotation, respectively. Although there seems to be no strength degradation until the end of the $1^{\text {st }}$ cycle of 0.03 rad of rotation for both positive and negative bending, investigating the stress fields available in ANSYS (2007) revealed that local flange buckling initiated at the end of the above-mentioned rotations/cycles. The analysis of the section with GFRP was stopped at the end of $0.03 \mathrm{rad}$ of rotation since the maximum interfacial and interlaminar shear strengths were previously exceeded. 


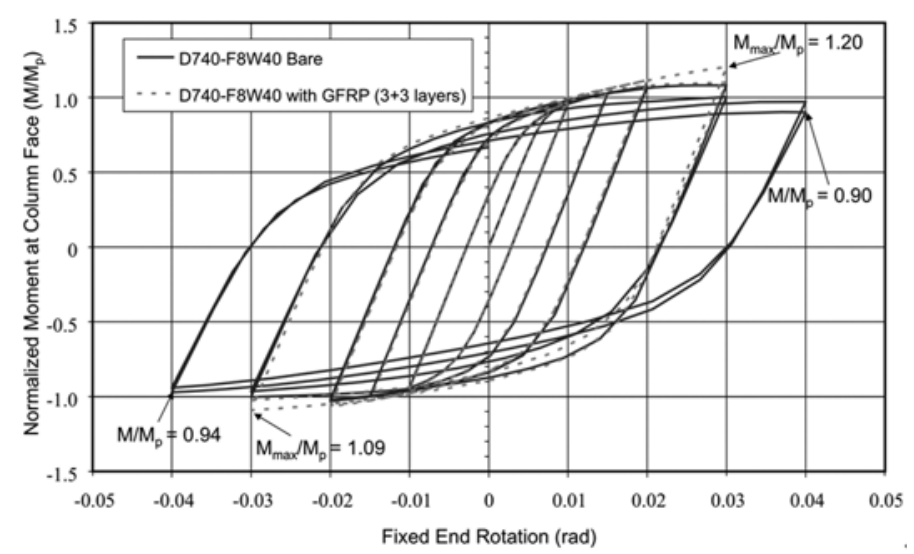

Fig. $14 \mathrm{M} / \mathrm{Mp}-\theta$ relationships of D740-F8W40 section with and without GFRP

The maximum normalized moments at the column face $\left(M_{\max } / M_{p}\right)$ were 1.09 and 1.20 for negative and positive bending, respectively, which were smaller or equal to the design moment of the connection. It can be observed in Fig. 14 that these values were actually achieved at the end of the $1^{\text {st }}$ cycle of $0.03 \mathrm{rad}$ of rotation, at which maximum interfacial shear strength was already exceeded. However, the assumption that steel-GFRP interaction and therefore the ability of GFRP strips to brace local buckles ends when the shear strength of the interface is exceeded can be unconservative when the aim is to determine the maximum moment that can be achieved in a real system. If the steel-GFRP interaction is still partly active even after the shear strength of the interface is exceeded at one or more locations throughout the GFRP strips, the maximum achieved moment can be higher than the moment achieved at the time when the shear strength was first exceeded. Hence, the $M_{\max } / M_{p}$ values presented in rows 8 and 9 in Table 4 are the maximum values observed in the $M / M_{p}-\theta$ graphs of GFRP reinforced sections.

The normalized moment at the column face - rotation at fixed end $\left(M / M_{p}-\theta\right)$ behavior of sections with depth/width ratio of 2.79 listed in Table 1 was examined. Table 4 presents the key results obtained from the $M / M_{p}-\theta$ behaviors of these sections. Columns 1,2 , and 3 indicate the section designation, number of layers together with the total thickness of GFRP in mm, and thickness of GFRP as a ratio of the thickness of the flange, respectively. The GFRP layer number and thickness presented in columns 2 and 3 are the thickest GFRP that could be used without exceeding the interfacial shear strength of the bond surface between steel and GFRP or interlaminar shear strength of GFRP laminates prior to local flange buckling. Interfacial and interlaminar shear stresses increased significantly once flange local buckling initiated. The $4^{\text {th }}$ and $6^{\text {th }}$ columns present last rotation/cycle of bare sections prior to local buckling for negative and positive bending, respectively. The $5^{\text {th }}$ and $7^{\text {th }}$ columns present the last rotation/cycle number of GFRP reinforced sections prior to local buckling for negative and positive bending, respectively. The $8^{\text {th }}$ and $9^{\text {th }}$ columns present $M_{\text {max }} / M_{p}$ values of GFRP reinforced sections for negative and positive bending, respectively. The $10^{\text {th }}$ and $11^{\text {th }}$ columns present $M / M_{p}$ values of bare sections at the end of the $2^{\text {nd }}$ cycle of $0.04 \mathrm{rad}$ of rotation for negative and positive bending, respectively. The maximum interfacial and interlaminar shear stresses of sections with GFRP at the last rotation/cycle prior to local buckling are presented in columns 12 and 13 for negative and positive bending, respectively. Maximum shear stresses generally occurred around the welded haunch stiffener for both flanges.

It can be seen from columns 2 and 3 that for all of the sections $3+3$ number of GFRP layers were the most that could be used without exceeding the interfacial shear strength of the bond surface between 
Table 4 FEA results for sections with depth/width ratio of 2.79

\begin{tabular}{|c|c|c|c|c|c|c|c|c|c|c|c|c|c|}
\hline & 1 & 2 & 3 & 4 & 5 & 6 & 7 & 8 & 9 & 10 & 11 & 12 & 13 \\
\hline & \multirow{3}{*}{$\begin{array}{c}\text { Section } \\
\text { Designation }\end{array}$} & \multirow{3}{*}{$\begin{array}{l}\text { \# of Layers } \\
\text { (Total } \\
\text { thickness } \\
\text { of GFRP) }\end{array}$} & \multirow{3}{*}{$\mathrm{t}_{\mathrm{GFRP}}$} & \multicolumn{4}{|c|}{$\begin{array}{l}\text { Last Rotation/Cycle Prior to Local Buck- } \\
\text { ling }\end{array}$} & \multirow{2}{*}{\multicolumn{2}{|c|}{$\begin{array}{l}\mathrm{M}_{\max } / \mathrm{M}_{\mathrm{p}} \text { for Sec- } \\
\text { tions with GFRP }\end{array}$}} & \multirow{2}{*}{\multicolumn{2}{|c|}{$\begin{array}{c}M / M_{p} @ \text { the end of } \\
2^{\text {nd }} \text { Cycle of } 0.04 \\
\text { rad of Rotation for } \\
\text { Bare Sections }\end{array}$}} & \multirow{2}{*}{\multicolumn{2}{|c|}{$\begin{array}{c}\text { Max Shear Stresses } \\
\text { @ Last Rotation/ } \\
\text { Cycle Prior to Local } \\
\text { Buckling }\end{array}$}} \\
\hline & & & & \multicolumn{2}{|c|}{ Negative Bending } & \multicolumn{2}{|c|}{ Positive Bending } & & & & & & \\
\hline & & & & $\begin{array}{c}\text { Bare } \\
\text { Section } \\
\end{array}$ & $\begin{array}{c}\text { Section } \\
\text { w/ GFRP }\end{array}$ & $\begin{array}{c}\text { Bare } \\
\text { Section } \\
\end{array}$ & $\begin{array}{c}\text { Section } \\
\text { w/ GFRP }\end{array}$ & $\begin{array}{l}\text { Negative } \\
\text { Bending }\end{array}$ & $\begin{array}{l}\text { Positive } \\
\text { Bending }\end{array}$ & $\begin{array}{l}\text { Negative } \\
\text { Bending }\end{array}$ & $\begin{array}{l}\text { Positive } \\
\text { Bending } \\
\end{array}$ & Interfacial & $\begin{array}{c}\text { Interlami- } \\
\text { nar }\end{array}$ \\
\hline 1 & D740-F8W40 & $\begin{array}{c}3+3 \\
(5.4 \mathrm{~mm})\end{array}$ & $0.33 t_{f}$ & $0.020 / 1^{\mathrm{st}}$ & $0.020 / 2^{\text {nd }}$ & $0.020 / 2^{\text {nd }}$ & $0.025 / 1^{\mathrm{st}}$ & 1.09 & 1.20 & 0.94 & 0.90 & 13.0 & 13.1 \\
\hline 2 & D740-F8W45 & $\begin{array}{c}3+3 \\
(5.4 \mathrm{~mm})\end{array}$ & $0.33 t_{f}$ & $0.020 / 1^{\mathrm{st}}$ & $0.020 / 2^{\text {nd }}$ & $0.020 / 2^{\text {nd }}$ & $0.025 / 1^{\mathrm{st}}$ & 1.06 & 1.12 & 0.91 & 0.87 & 13.4 & 14.6 \\
\hline 3 & D740-F8W50 & $\begin{array}{c}3+3 \\
(5.4 \mathrm{~mm})\end{array}$ & $0.33 t_{f}$ & $0.015 / 2^{\text {nd }}$ & $0.020 / 1^{\mathrm{st}}$ & $0.020 / 1^{\mathrm{st}}$ & $0.020 / 2^{\text {nd }}$ & 1.05 & 1.10 & 0.89 & 0.88 & 13.3 & 14.1 \\
\hline 4 & D740-F8W55 & $\begin{array}{c}3+3 \\
(5.4 \mathrm{~mm})\end{array}$ & $0.33 t_{f}$ & $0.015 / 2^{\text {nd }}$ & $0.018 / 1^{\mathrm{st}}$ & $0.020 / 1^{\mathrm{st}}$ & $0.020 / 2^{\text {nd }}$ & 1.00 & 1.09 & 0.88 & 0.86 & 13.3 & 14.3 \\
\hline 5 & D740-F8W60 & $\begin{array}{c}3+3 \\
(5.4 \mathrm{~mm})\end{array}$ & $0.33 t_{f}$ & $0.015 / 1^{\mathrm{st}}$ & $0.015 / 2^{\text {nd }}$ & $0.015 / 2^{\text {nd }}$ & $0.020 / 1^{\mathrm{st}}$ & 0.99 & 1.07 & 0.86 & 0.84 & 14.3 & 14.6 \\
\hline 6 & D740-F9W40 & $\begin{array}{c}3+3 \\
(5.4 \mathrm{~mm})\end{array}$ & $0.37 t_{f}$ & $0.015 / 1^{\mathrm{st}}$ & $0.015 / 2^{\text {nd }}$ & $0.020 / 2^{\text {nd }}$ & $0.023 / 1^{\mathrm{st}}$ & 1.04 & 1.18 & 0.91 & 0.84 & 12.4 & 13.9 \\
\hline 7 & D740-F9W45 & $\begin{array}{c}3+3 \\
(5.4 \mathrm{~mm})\end{array}$ & $0.37 t_{f}$ & $0.015 / 1^{\mathrm{st}}$ & $0.015 / 2^{\text {nd }}$ & $0.020 / 2^{\text {nd }}$ & $0.023 / 1^{\mathrm{st}}$ & 1.03 & 1.09 & 0.88 & 0.84 & 12.7 & 13.9 \\
\hline 8 & D740-F9W50 & $\begin{array}{c}3+3 \\
(5.4 \mathrm{~mm})\end{array}$ & $0.37 t_{f}$ & $0.015 / 1^{\mathrm{st}}$ & $0.015 / 2^{\text {nd }}$ & $0.020 / 1^{\mathrm{st}}$ & $0.020 / 2^{\text {nd }}$ & 0.99 & 1.08 & 0.86 & 0.84 & 13.1 & 14.1 \\
\hline 9 & D740-F9W55 & $\begin{array}{c}3+3 \\
(5.4 \mathrm{~mm})\end{array}$ & $0.37 t_{f}$ & $0.015 / 1^{\mathrm{st}}$ & $0.015 / 2^{\text {nd }}$ & $0.017 / 1^{\mathrm{st}}$ & $0.020 / 1^{\mathrm{st}}$ & 0.99 & 1.08 & 0.85 & 0.82 & 13.4 & 15.0 \\
\hline 10 & D740-F9W60 & $\begin{array}{c}3+3 \\
(5.4 \mathrm{~mm})\end{array}$ & $0.37 t_{f}$ & $0.015 / 1^{\mathrm{st}}$ & $0.015 / 2^{\text {nd }}$ & $0.015 / 2^{\text {nd }}$ & $0.017 / 1^{\mathrm{st}}$ & 0.99 & 1.05 & 0.84 & 0.79 & 13.3 & 13.6 \\
\hline 11 & D740-F10W40 & $\begin{array}{c}3+3 \\
(5.4 \mathrm{~mm})\end{array}$ & $0.41 t_{f}$ & $0.015 / 2^{\text {nd }}$ & $0.015 / 2^{\text {nd }}$ & $0.020 / 1^{\mathrm{st}}$ & $0.020 / 1^{\mathrm{st}}$ & 1.01 & 1.09 & 0.87 & 0.83 & 11.9 & 13.9 \\
\hline 12 & D740-F10W45 & $\begin{array}{c}3+3 \\
(5.4 \mathrm{~mm})\end{array}$ & $0.41 t_{f}$ & $0.015 / 2^{\text {nd }}$ & $0.015 / 2^{\text {nd }}$ & $0.020 / 1^{\mathrm{st}}$ & $0.020 / 1^{\mathrm{st}}$ & 0.99 & 1.08 & 0.85 & 0.78 & 12.3 & 13.8 \\
\hline 13 & D740-F10W50 & $\begin{array}{c}3+3 \\
(5.4 \mathrm{~mm})\end{array}$ & $0.41 t_{f}$ & $0.015 / 1^{\text {st }}$ & $0.015 / 2^{\text {nd }}$ & $0.018 / 1^{\mathrm{st}}$ & $0.020 / 1^{\mathrm{st}}$ & 0.99 & 1.08 & 0.81 & 0.78 & 12.6 & 13.8 \\
\hline 14 & D740-F10W55 & $\begin{array}{c}3+3 \\
(5.4 \mathrm{~mm})\end{array}$ & $0.41 t_{f}$ & $0.015 / 1^{\mathrm{st}}$ & $0.015 / 2^{\text {nd }}$ & $0.015 / 2^{\text {nd }}$ & $0.020 / 1^{\mathrm{st}}$ & 0.98 & 1.07 & 0.81 & 0.77 & 12.9 & 13.8 \\
\hline 15 & D740-F10W60 & $\begin{array}{c}3+3 \\
(5.4 \mathrm{~mm})\end{array}$ & $0.41 t_{f}$ & $0.014 / 1^{\mathrm{st}}$ & $0.015 / 2^{\text {nd }}$ & $0.015 / 2^{\text {nd }}$ & $0.016 / 1^{\mathrm{st}}$ & 0.97 & 1.02 & 0.81 & 0.76 & 13.3 & 13.8 \\
\hline
\end{tabular}


steel and GFRP prior to local buckling. The interfacial shear stresses achieved for the sections prior to local flange buckling ranged between 11.9 to $13.4 \mathrm{MPa}$, which were somewhat close to the accepted interfacial shear strength $(15.0 \mathrm{MPa})$ of the bond surface. The interlaminar shear stresses of the sections ranged between 13.1 and $15.0 \mathrm{MPa}$. The interfacial shear strength of GFRP strips was taken as $18 \mathrm{MPa}$. Results presented in columns 8 and 9 show that the design moment capacity of the connection $\left(1.2 M_{p}\right)$ was not exceeded neither in negative nor positive bending in any of the sections. The largest normalized column face moment occurred in section D740-F8W40 at positive bending with 1.20 . The results presented in columns 10 and 11 show that strength degradation in most of the sections was below $20 \%$ at the end of the $2^{\text {nd }}$ cycle of $0.04 \mathrm{rad}$ of rotation. Sections D740-F9W60/F10W45/F10W50/F10W55/ F10W60 experienced strength degradations in excess of $20 \%$ at the end of the $2^{\text {nd }}$ cycle of 0.04 rad of rotation, especially in positive bending.

For bare sections initial local flange buckling occurred at a lower rotation/cycle at the bottom flange than the top flange, which was consistent with the implemented imperfections in the models. In negative bending almost none of the bare sections reached 0.02 rad of rotation without local buckling. Only sections D740-F8W40 and D740-F8W45 reached the first cycle of $0.02 \mathrm{rad}$ of rotation without any local buckling. However, in positive bending bare sections D740-F8W40/F8W45/F9W40/F9W45 completed the two cycles of 0.02 rad of rotation and sections D740-F8W50/F8W55/F9W50/F10W40/ F10W45 completed the first cycle of 0.02 rad of rotation without any local buckling.

Comparison of the rotation values of bare sections with sections with GFRP strips reveals that the addition of 3+3 layers of GFRP increased the rotation capacity of bare sections prior to local buckling by at least one cycle in both negative and positive bendings. The only exception to this was section D740-F10W60 in positive bending, which was the most slender section among all sections with a depth/width ratio of 2.79 . The addition of $3+3$ layers of GFRP enabled almost all of the sections to reach to 0.02 rad of rotation in positive bending. Sections D740-F9W60 and D740-F10W60 reached only 0.017 and 0.016 rad of rotations in positive bending, respectively, with the addition of the GFRP strips. In negative bending the addition of $3+3$ layers of GFRP strips enabled all of the sections to complete 2 cycles at 0.015 rad of rotation or higher without any local buckling. Sections D740-F8W40 and D740-F8W45 completed the full 2 cycles of 0.02 rad of rotation, section D740-F8W50 completed the first cycle of $0.02 \mathrm{rad}$ of rotation, and section D740-F8W55 completed the first cycle of $0.018 \mathrm{rad}$ of rotation. The rest of the sections completed the second cycle of 0.015 rad of rotation in negative bending without any local buckling.

Examining the rotations in positive bending of sections D740-F8W40/F8W45 and D740-F9W40/ F9W45 indicates that the contribution of the GFRP strips to the rotation capacity of the sections decreases with increasing FSR. While the rotation capacities in positive bending of bare sections D740-F8W40/ F8W45 and D740-F9W40/F9W45 with no local buckling were the same (second cycle of 0.02 rad of rotation), the rotation capacities with no local buckling differed with the addition of GFRP strips to these sections. While sections D740-F8W40/F8W45 with an FSR of 8 were capable of reaching the end of the $1^{\text {st }}$ cycle of 0.025 rad of rotation with the addition of the GFRP strips, sections D740-F9W40/ F9W45 with an FSR of 9 reached the end of the $1^{\text {st }}$ cycle of $0.023 \mathrm{rad}$ of rotation with the addition of the GFRP strips without any local buckling. The same comment could be made for the relationship between WSR and contribution of GFRP reinforcement. Comparison of the rotation values prior to local buckling of section D740-F8W50 and D740-F8W55 in negative bending shows that the contribution of GFRP strips decreases as the WSR of the sections increase. The addition of $3+3$ layers of GFRP strips to section D740-F8W50 with WSR of 50 increased the rotation capacity of the section to 0.02 rad of rotation from $0.015 \mathrm{rad}$ of rotation. However, for section D740-F8W55 with WSR of 55 the addition 
of $3+3$ layers of GFRP strips increased the rotation capacity of the section to 0.018 rad of rotation from $0.015 \mathrm{rad}$ of rotation.

\section{Sections with depth/width ratio of 2.10}

Table 5 presents results from the $M / M_{p^{-}} \theta$ behaviors of sections with depth/width ratio of 2.10 . For bare sections the rotation capacities that were achieved without any local buckling or strength degradation were around $0.030 \mathrm{rad}$ and $0.020 \mathrm{rad}$ for positive and negative bending, respectively. The results presented in columns 10 and 11 shows that the strength degradations at the end of $2^{\text {nd }}$ cycle of $0.04 \mathrm{rad}$ of rotation were more than $20 \%$ for almost all of the sections. Only section D556-F8W40 experienced degradations below $20 \%$. All of the other sections suffered strength degradations in excess of $20 \%$ either only at negative bending or at both negative and positive bending. Using $3+3$ layers of GFRP strips for sections with FSR of 8 and 9 caused the interlaminar shear strength of GFRP strips to be exceeded. Therefore, $2+2$ layers of GFRP strips were the thickest layer that could be used for these sections without the interlaminar shear strength being exceeded. For sections with an FSR of $103+3$ layers of GFRP strips could be used.

Comparison of the rotation values prior to local buckling of bare sections with sections with GFRP (columns 4, 5, 6, and 7) shows that in negative bending the addition of GFRP strips did not increase the rotation capacity of the sections. Only sections D556-F10W40 and D-556-F10W45 showed a slight increase, which was not significant to consider. In positive bending only four out of the nine sections showed an increase in the rotation capacity. The rotation capacities in positive bending of sections D556-F8W45/F8W50/F9W50/F10W40 increased to the $2^{\text {nd }}$ cycle of $0.03 \mathrm{rad}, 2^{\text {nd }}$ cycle of $0.03 \mathrm{rad}, 1^{\text {st }}$ cycle of $0.03 \mathrm{rad}$, and $1^{\text {st }}$ cycle of $0.025 \mathrm{rad}$ from the $1^{\text {st }}$ cycle of $0.03 \mathrm{rad}, 1^{\text {st }}$ cycle of $0.03 \mathrm{rad}, 2^{\text {nd }}$ cycle of $0.020 \mathrm{rad}$, and $2^{\text {nd }}$ cycle of $0.020 \mathrm{rad}$, respectively. The maximum normalized column face moment of sections with GFRP was 1.15, which was achieved by section D556-F8W40 in positive bending.

\section{Sections with depth/width ratio of $\mathbf{1 . 3 8}$}

Table 6 presents results from the $M / M_{p^{-}} \theta$ behaviors of sections with depth/width ratio of 1.38 . The results presented in column 4 and 6 reveal that the rotation capacities of the bare sections prior to local flange buckling were around $0.04 \mathrm{rad}$ and $0.03 \mathrm{rad}$ for positive and negative bending, respectively. In addition, the strength degradations of the bare sections at the end of $2^{\text {nd }}$ cycle of 0.04 rad of rotation were below 20\%. For sections D365-F8W30/F8W35/F8W40/F9W35/F9W40 the addition of even 1+1 layers of GFRP strips caused the interfacial shear strength of the bond surface between steel and GFRP to be exceeded prior to local buckling of the flanges. For sections D365-F9W35/F10W30/F10W35/ F10W40 interfacial shear stresses developed at the bond surface between steel and 1+1 layers of GFRP remained below the accepted interfacial shear strength. Although the interfacial shear strength was not exceeded for these sections with 1+1 layers of GFRP strips, the GFRP reinforcement did not improve the rotation capacities of these three sections, as can be observed by comparing the rotation values presented in columns 4-5 and 6-7.

The reason behind the incapability of GFRP strips to brace local buckles in shallow sections probably lies in the shorter depths of these sections. Since the flange widths of all the sections (shallow or deep) that were analyzed are the same, as the depth of the sections gets shorter, the coupling forces in the 
Table 5 FEA results for sections with depth/width ratio of 2.10

\begin{tabular}{|c|c|c|c|c|c|c|c|c|c|c|c|c|c|}
\hline & 1 & 2 & 3 & 4 & 5 & 6 & 7 & 8 & 9 & 10 & 11 & 12 & 13 \\
\hline & \multirow{3}{*}{$\begin{array}{c}\text { Section } \\
\text { Designation }\end{array}$} & \multirow{3}{*}{$\begin{array}{l}\text { \# of Layers } \\
\text { (Total } \\
\text { thickness of } \\
\text { GFRP) }\end{array}$} & \multirow{3}{*}{$\mathrm{t}_{\mathrm{GFRP}}$} & \multicolumn{4}{|c|}{$\begin{array}{l}\text { Last Rotation/Cycle Prior to } \\
\text { Local Buckling }\end{array}$} & \multirow{2}{*}{\multicolumn{2}{|c|}{$\begin{array}{l}\mathrm{M}_{\max } / \mathrm{M}_{\mathrm{p}} \text { for Sec- } \\
\text { tions with GFRP }\end{array}$}} & \multirow{2}{*}{\multicolumn{2}{|c|}{$\begin{array}{c}\mathrm{M} / \mathrm{M}_{\mathrm{p}} @ \text { the end of } \\
2^{\text {nd }} \text { Cycle of } 0.04 \\
\text { rad of Rotation for } \\
\text { Bare Sections }\end{array}$}} & \multirow{2}{*}{\multicolumn{2}{|c|}{$\begin{array}{c}\text { Max Shear Stresses } \\
\text { @ Last Rotation/ } \\
\text { Cycle Prior to Local } \\
\text { Buckling }\end{array}$}} \\
\hline & & & & Negative & Bending & Positive & Bending & & & & & & \\
\hline & & & & $\begin{array}{l}\text { Bare } \\
\text { Section }\end{array}$ & $\begin{array}{l}\text { Section } \\
\text { w/ GFRP }\end{array}$ & $\begin{array}{l}\text { Bare } \\
\text { Section }\end{array}$ & $\begin{array}{l}\text { Section } \\
\text { w/ GFRP }\end{array}$ & $\begin{array}{l}\text { Negative } \\
\text { Bending }\end{array}$ & $\begin{array}{l}\text { Positive } \\
\text { Bending }\end{array}$ & $\begin{array}{l}\text { Negative } \\
\text { Bending }\end{array}$ & $\begin{array}{l}\text { Positive } \\
\text { Bending }\end{array}$ & Interfacial & $\begin{array}{l}\text { Interlami- } \\
\text { nar }\end{array}$ \\
\hline 1 & D556-F8W40 & $\begin{array}{c}2+2 \\
(3.6 \mathrm{~mm})\end{array}$ & $0.22 t_{f}$ & $0.020 / 2^{\text {nd }}$ & $0.020 / 2^{\text {nd }}$ & $0.035 / 1^{\text {st }}$ & $0.035 / 1^{\mathrm{st}}$ & 1.01 & 1.15 & 0.84 & 1.01 & 10.5 & 16.4 \\
\hline 2 & D556-F8W45 & $\begin{array}{c}2+2 \\
(3.6 \mathrm{~mm})\end{array}$ & $0.22 t_{f}$ & $0.020 / 2^{\text {nd }}$ & $0.020 / 2^{\text {nd }}$ & $0.030 / 1^{\mathrm{st}}$ & $0.030 / 2^{\text {nd }}$ & 0.97 & 1.06 & 0.79 & 0.86 & 10.9 & 16.3 \\
\hline 3 & D556-F8W50 & $\begin{array}{c}2+2 \\
(3.6 \mathrm{~mm})\end{array}$ & $0.22 t_{f}$ & $0.020 / 2^{\text {nd }}$ & $0.020 / 2^{\text {nd }}$ & $0.030 / 1^{\mathrm{st}}$ & $0.030 / 2^{\text {nd }}$ & 0.96 & 1.07 & 0.76 & 0.82 & 10.8 & 15.9 \\
\hline 4 & D556-F9W40 & $\begin{array}{c}2+2 \\
(3.6 \mathrm{~mm})\end{array}$ & $0.22 t_{f}$ & $0.020 / 1^{\mathrm{st}}$ & $0.020 / 1^{\mathrm{st}}$ & $0.030 / 1^{\text {st }}$ & $0.030 / 1^{\mathrm{st}}$ & 0.93 & 1.05 & 0.72 & 0.86 & 10.4 & 16.5 \\
\hline 5 & D556-F9W45 & $\begin{array}{c}2+2 \\
(3.6 \mathrm{~mm})\end{array}$ & $0.22 t_{f}$ & $0.020 / 1^{\mathrm{st}}$ & $0.020 / 1^{\text {st }}$ & $0.030 / 1^{\text {st }}$ & $0.030 / 1^{\mathrm{st}}$ & 0.91 & 1.04 & 0.69 & 0.80 & 10.6 & 16.2 \\
\hline 6 & D556-F9W50 & $\begin{array}{c}2+2 \\
(3.6 \mathrm{~mm})\end{array}$ & $0.22 t_{f}$ & $0.020 / 1^{\mathrm{st}}$ & $0.020 / 1^{\mathrm{st}}$ & $0.020 / 2^{\text {nd }}$ & $0.030 / 1^{\mathrm{st}}$ & 0.9 & 1.03 & 0.66 & 0.77 & 10.7 & 15.8 \\
\hline 7 & D556-F10W40 & $\begin{array}{c}3+3 \\
(5.4 \mathrm{~mm})\end{array}$ & $0.41 t_{f}$ & $0.015 / 2^{\text {nd }}$ & $0.018 / 1^{\mathrm{st}}$ & $0.020 / 2^{\text {nd }}$ & $0.025 / 1^{\mathrm{st}}$ & 0.91 & 1.04 & 0.67 & 0.80 & 10.1 & 13.5 \\
\hline 8 & D556-F10W45 & $\begin{array}{c}3+3 \\
(5.4 \mathrm{~mm})\end{array}$ & $0.41 t_{f}$ & $0.015 / 2^{\text {nd }}$ & $0.018 / 1^{\mathrm{st}}$ & $0.020 / 2^{\text {nd }}$ & $0.020 / 2^{\text {nd }}$ & 0.89 & 0.99 & 0.62 & 0.76 & 10.4 & 13.6 \\
\hline 9 & D556-F10W50 & $\begin{array}{c}3+3 \\
(5.4 \mathrm{~mm})\end{array}$ & $0.41 t_{f}$ & $0.015 / 2^{\text {nd }}$ & $0.015 / 2^{\text {nd }}$ & $0.020 / 2^{\text {nd }}$ & $0.020 / 2^{\text {nd }}$ & 0.87 & 0.96 & 0.60 & 0.71 & 10.8 & 13.3 \\
\hline
\end{tabular}


Table 6 FEA results for sections with depth/width ratio of 1.38

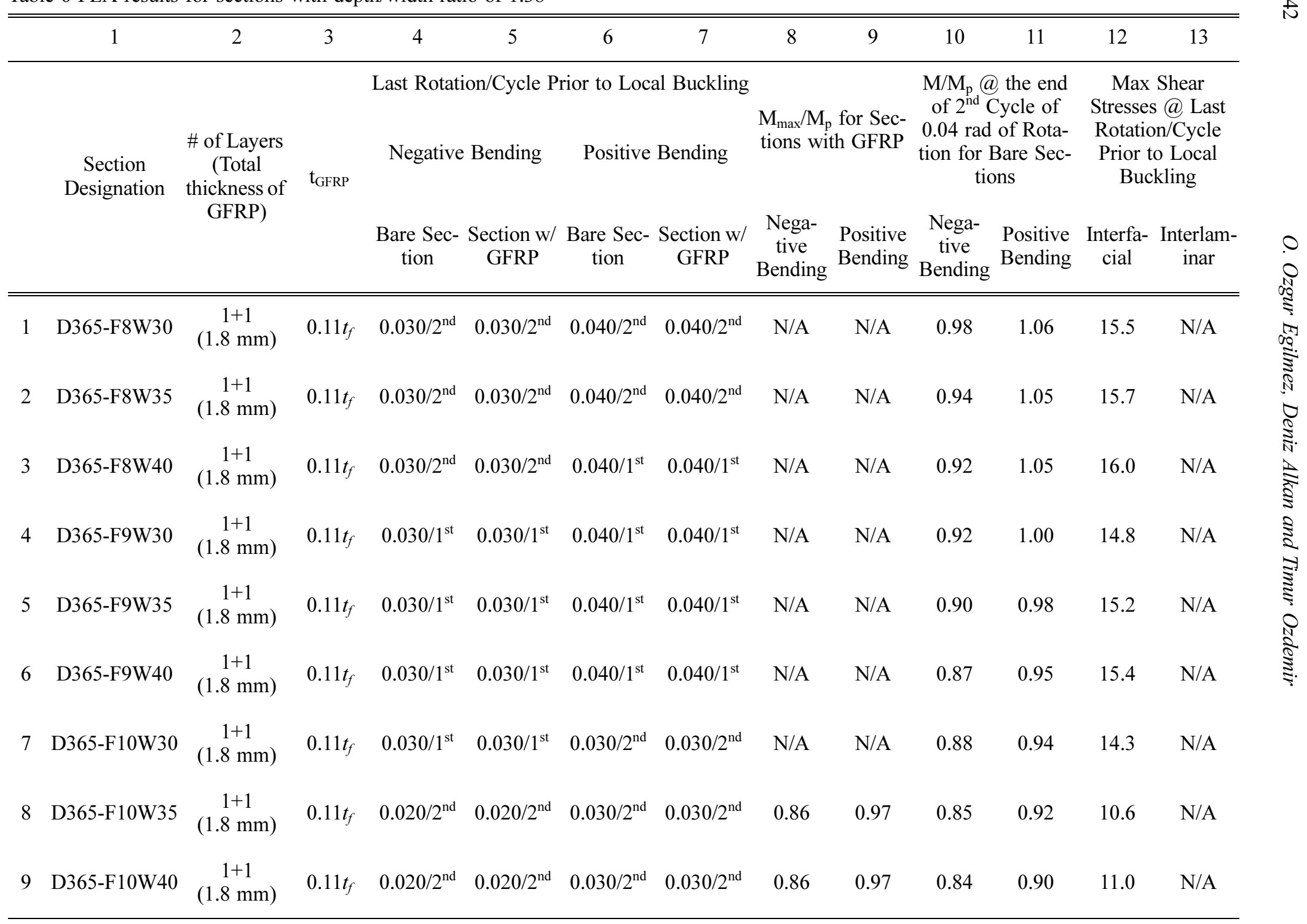


flanges get higher under high moments. Higher forces in the flanges will result in higher shear forces to be transferred to the GFRP strips, which could exceed the interfacial shear strength of the adhesive layer between steel and GFRP. This type of an action could limit the bracing effect of GFRP strips.

\section{Conclusions}

This paper presents results from an analytical study targeted at improving the understanding of the cyclic behavior of steel I-beams modified by a welded haunch at the bottom flange and reinforced with GFRP strips at the plastic hinge region. Modified steel sections with flange slenderness ratios exceeding the slenderness limits set forth in current seismic design codes were the main focus of the study. The results from finite element analyses demonstrate that the GFRP strips may provide bracing to the flanges against the occurrence of plastic local buckling and the rotation capacities of deep beams modified by a WH can be moderately improved by reinforcing the plastic hinge region with GFRP. The weakest link in a steel-GFRP composite action under high cyclic flexure appears to be the interfacial shear strength of the adhesive layer between the steel and GFRP. The negative effects of peeling stresses on debonding were neglected.

Results from the present work also indicate that it does not seem possible to rely on GFRP reinforcement to increase the flexural resistance of modified beam-column connections at a rotation of 0.04 radians, which is the target rotation for SMF. It appears that the adhesive layer between steel and GFRP fails in rotations much lower than 0.04 radians. However, if the bottom flange welded haunch modification is applied in an effort to moderately improve the seismic performance of the structure, then GFRP reinforcement can help the connections to maintain rotations in the order of 0.02 radians, which is required for intermediate moment frames, and may eliminate cumbersome repair works of buckled flanges and webs. It should also be noted that in order to rely on such a contribution, the design moment of the existing connection needs to be checked to make sure that it is not exceeded prior to debonding of the adhesive layer.

This analytical study is part of research program that also includes testing of full-scale cantilever beams under cyclic loading. Results from the experimental phase of the program will be combined with the results from this study to develop a better understanding on the cyclic behavior of beams reinforced with GFRP strips.

\section{Acknowledgements}

The writers gratefully acknowledge the funding provided by The Scientific and Technological Research Council of Turkey (TUBITAK). Partial funding from a reintegration grant provided by the European Commission and Izmir Institute of Technology is also acknowledged.

\section{References}

Accord, N.B. and Earls, C.J. (2006), "Use of fiber-reinforced polymer composite elements to enhance structural steel member ductility", J. Compos. Constr., ASCE, 10(4), 337-344.

American Institute of Steel Construction (AISC) (2005a), Seismic provisions for structural steel buildings, ANSI/ 
AISC 341-05, AISC, Chicago, IL.

American Institute of Steel Construction (AISC) (2005b), Code of standard practice for steel buildings and bridges, AISC, Chicago, IL.

American Institute of Steel Construction (AISC) (2005c), Prequalified connections for special and intermediate steel moment frames for seismic applications, ANSI/AISC 358-05, AISC, Chicago, IL.

American Institute of Steel Construction (AISC) (1999), Modification of existing welded steel moment connections for seismic resistance, Steel Design Guide Series 12, AISC, Chicago, IL.

ANSYS Inc. (2007), Finite element model users manual, Version 11.0, Canonsburg, Pa.

Boone, M.J. (2002), "Mechanical Testing of Epoxy Adhesives for Naval Applications", Master of Science Thesis, The Graduate School of The University of Maine, December.

Cadei, J.M.D., Stratford, T.J., Hollaway, L.C. and Duckett, W.G. (2004), Strengthening metallic structures using externally bonded fiber-reinforced polymers, CIRIA, Publication C595, London.

Chen, M. and Das, S. (2009), "Experimental study on repair of corroded steel beam using CFRP", Steel Compos. Struct., 9(2), 103-118.

Ekiz, E., El-Tawil, S., Parra-Montesinos, G. and Goel, S. (2004), "Enhancing plastic hinge behavior in steel flexural members using CFRP wraps", Proc. of the 13th World Conf. on Earthquake Engineering, Paper No. 2496, Vancouver.

El Damatty, A.A. and Abushagur, M. (2003), "Testing and modeling of shear and peel behavior for bonded steel/ FRP connections", Thin-Wall. Struct., 41, 987-1003.

Eurocode-8, Part 1, European Standard (2003), Design of structures for earthquake resistance- Part 1: General rules, seismic actions, and rules for buildings, prEN 1998-1: 2003 (E).

Federal Emergency Management Agency (FEMA) (2000a), Recommended seismic design criteria for new steel moment-frame buildings, FEMA 350, Washington, D.C.

Federal Emergency Management Agency (FEMA) (2000b), Recommended seismic evaluation and upgrade for existing welded steel moment-frame buildings, FEMA 351, Washington, D.C.

Guven, C.A. (2009), "Experimental study on improving local buckling behavior of steel plates with glass fiber reinforced polymers", MS Thesis, Izmir Institute of Technology, March.

Lili, S., Yan, Z., Yuexin, D. and Zuoguang, Z. (2008), "Interlaminar Shear Property of Modified Glass Fiber Reinforced Polymer with Different MWCNTs", Chinese Journal of Aeronautics, 21, 361-369.

Nakashima, M., Suita, K., Morisako, K. and Maruoka, Y. (1998), "Tests of welded beam-column subassemblies I: Global behavior", J. Struct. Eng. ASCE, 124(11), 1236-1244.

Nakashima, M., Kanao, I. and Liu, D. (2002), "Lateral instability and lateral bracing of steel beams subjected to cyclic loading", J. Struct. Eng. ASCE, 128(10), 1308-1316.

Nakashima, M., Liu, D. and Kanao, I. (2003), "Lateral-torsional and local instability of steel beams subjected to large cyclic loading", J. Steel Struct., 3(3), 179-189.

Okazaki, T., Liu, D., Nakashima, M. and Engelhardt, M.D. (2006), "Stability requirements for beams in seismic steel moment frames", J. Struct. Eng. ASCE, 132(9), 1334-1342.

SAC (1996), "Technical report: Experimental investigations of beam-column subassemblies", Report No. SAC96-01, SAC Joint Venture, Sacramento, California.

Sayed-Ahmet, E.Y. (2004), "Strengthening of thin-walled steel I-section beams using CFRP strips", Proc. of the 4th Advanced Composites for Bridges and Structures Conf., Calgary, Canada.

Schnerch, D., Dawood, M., Rizkalla, S. and Sumner, E. (2007), "Proposed design guidelines for strengthening of steel bridges with FRP materials", Constr. Build. Mater., 21(5), 1001-1010.

Uang, C., Yu, Q.K., Noel, S. and Gross, J. (2000), "Cyclic testing of steel moment connections rehabilitated with RBS or welded haunch", J. Struct. Eng. ASCE, 126(1), 57-68. 